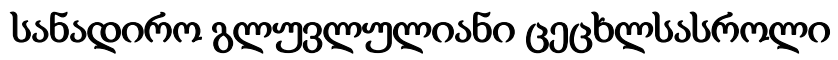

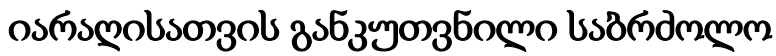

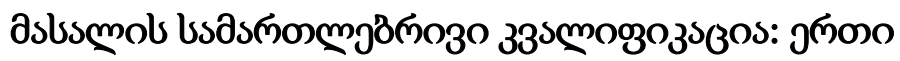

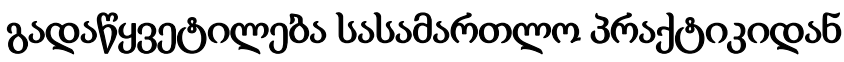

\author{
зомпво добдовsdg*
}

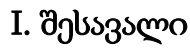

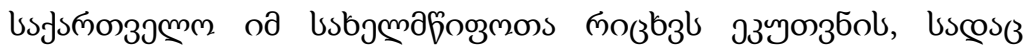

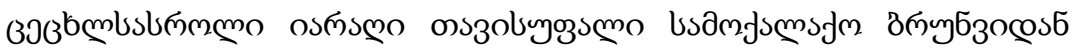

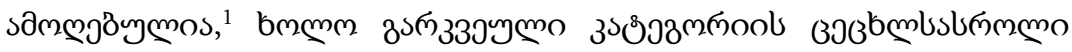

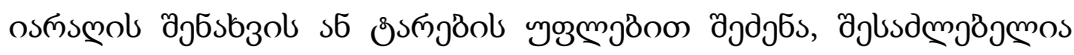

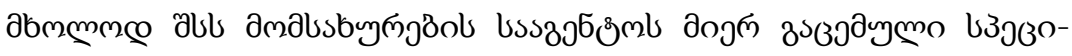

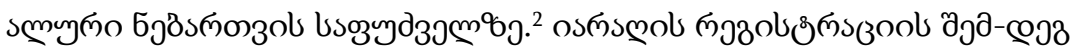

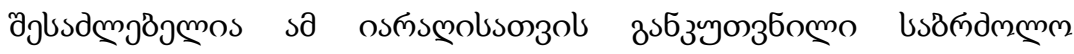

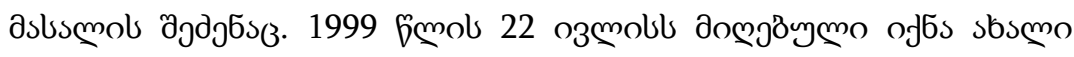

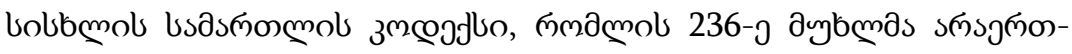

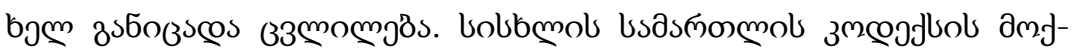

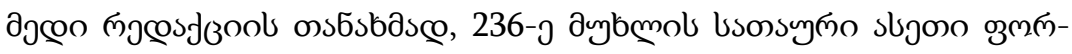

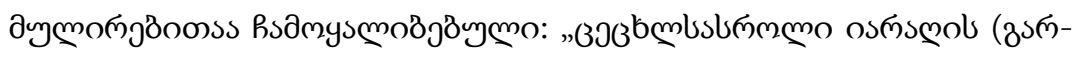

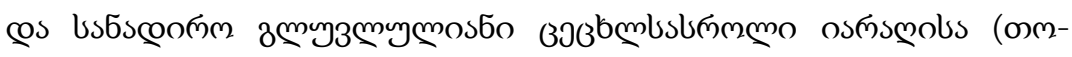

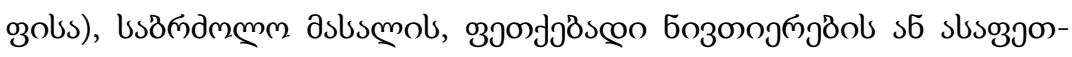

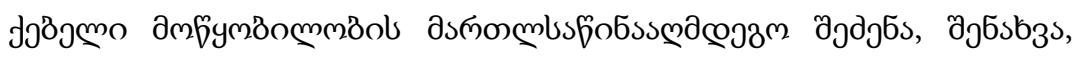

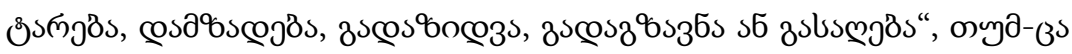

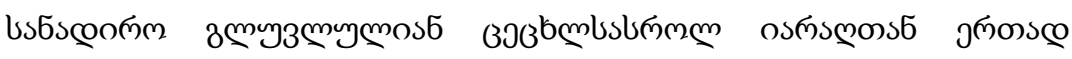

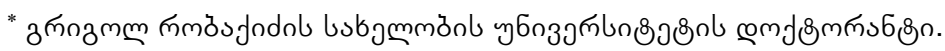
orcid.org/0000-0003-3167-6436.

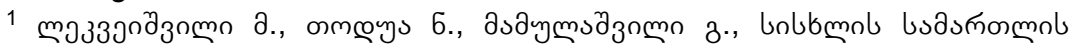

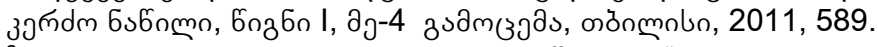

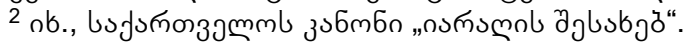




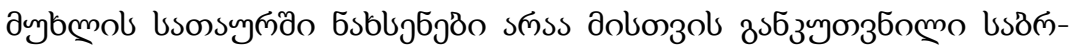

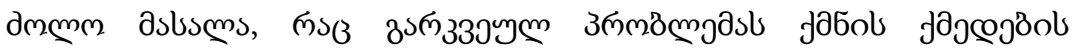

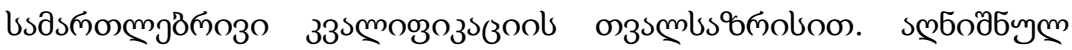

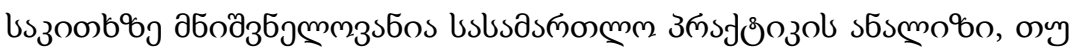

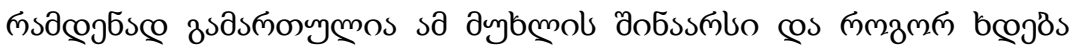

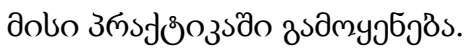

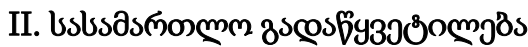

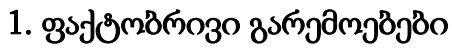

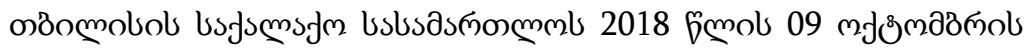

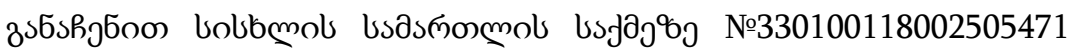

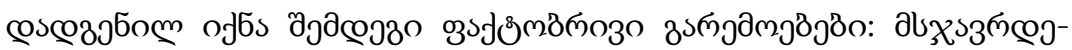

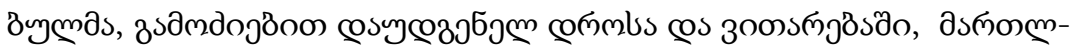

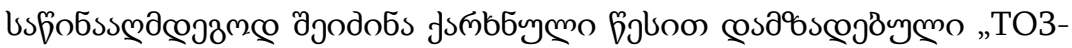

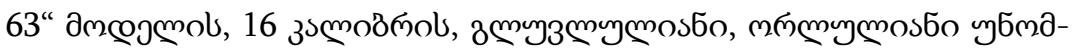

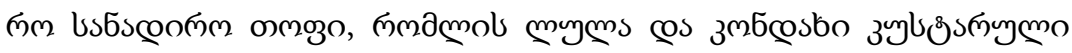

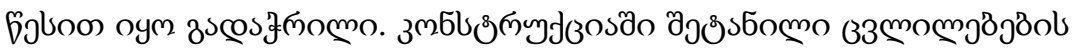

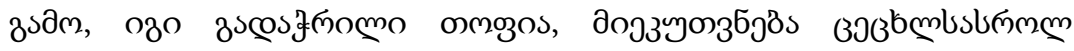

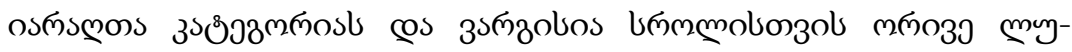

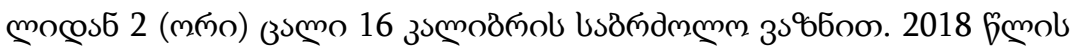

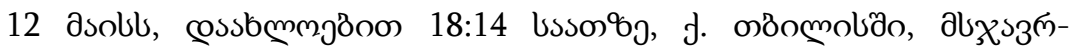

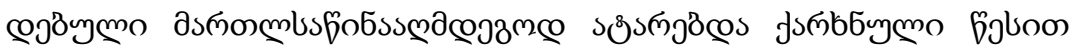

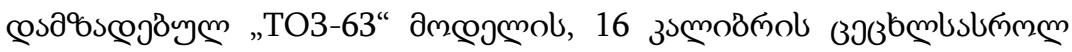

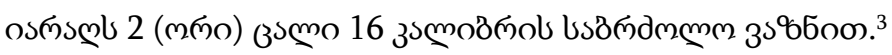

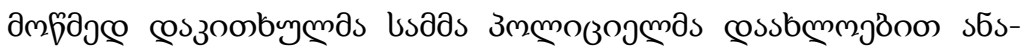

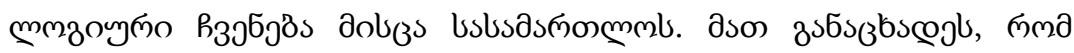

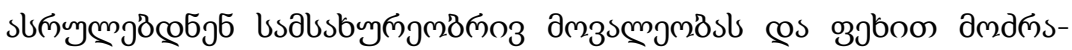

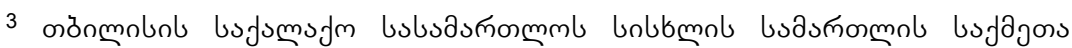

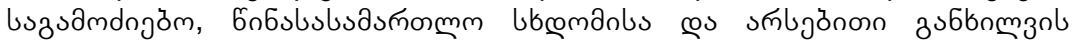

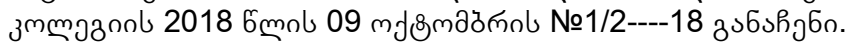




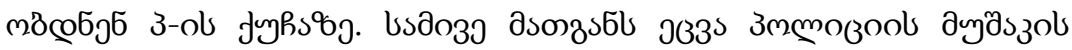

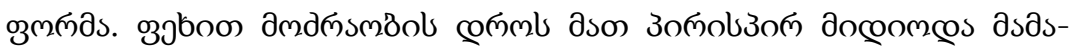

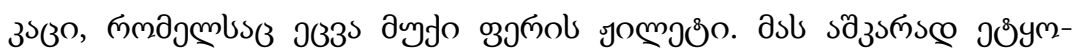

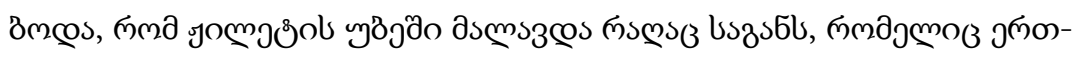
j๓о амдјб

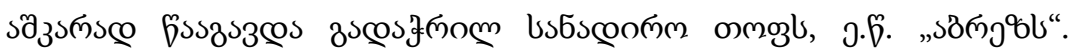

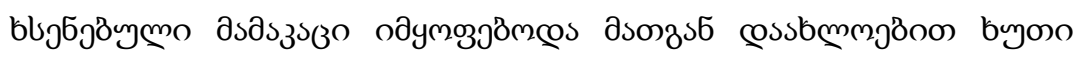

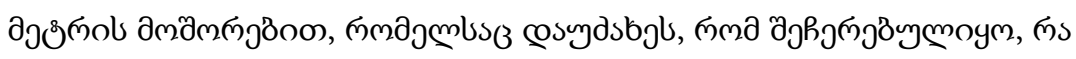

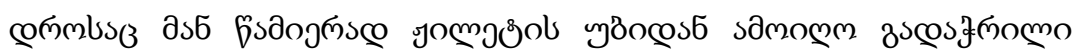

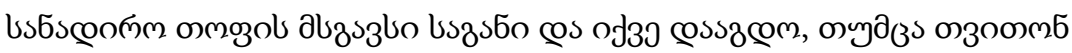

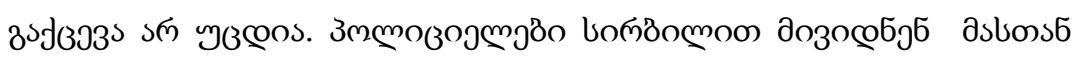

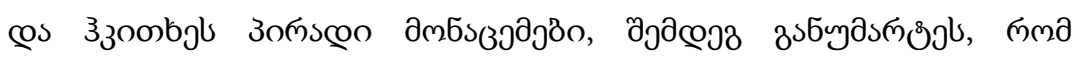

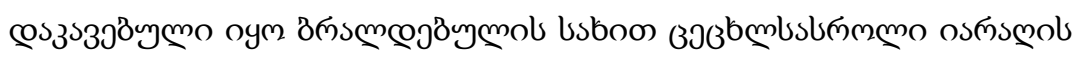

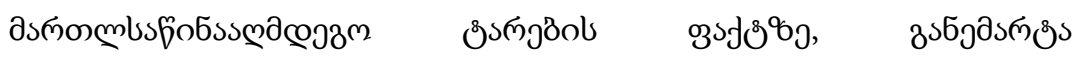

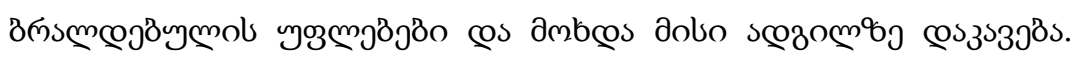

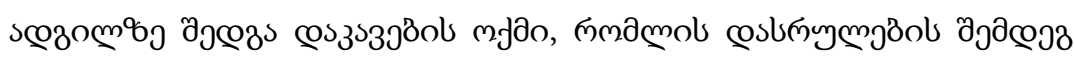

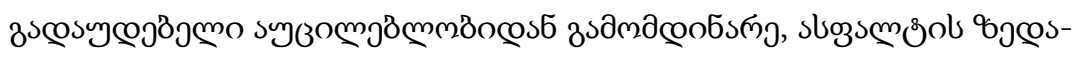

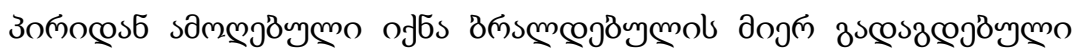

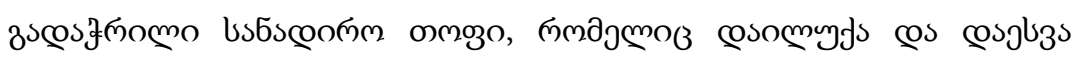

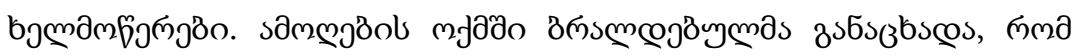

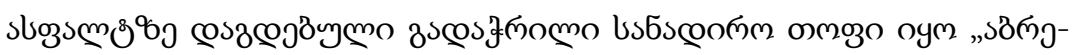

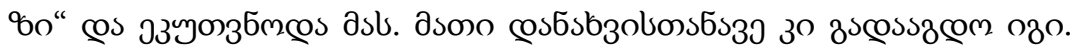

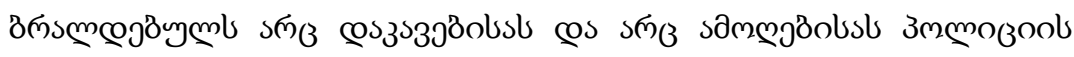

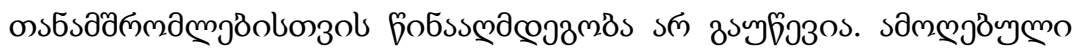

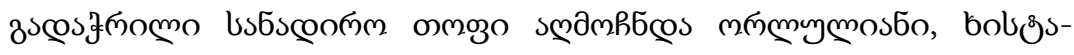

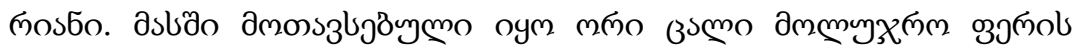

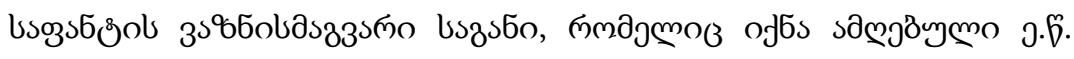

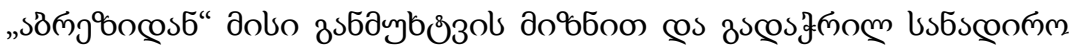

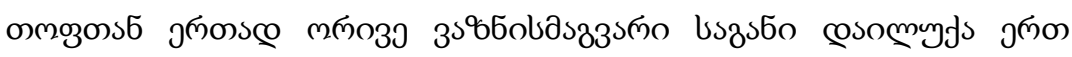

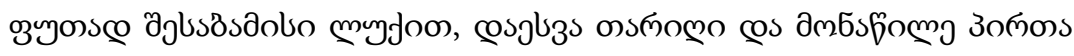

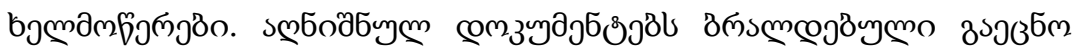




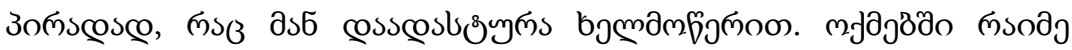

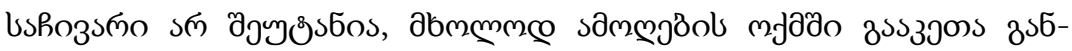

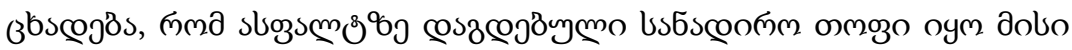

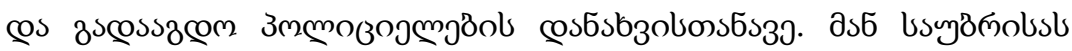

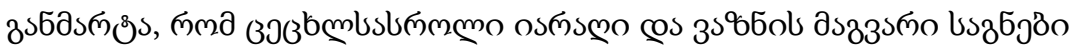

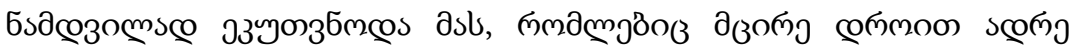

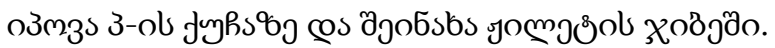

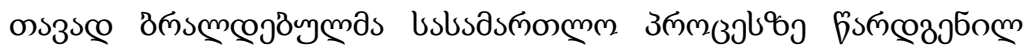

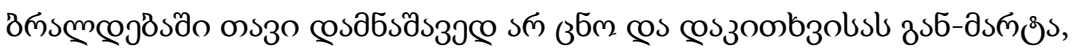

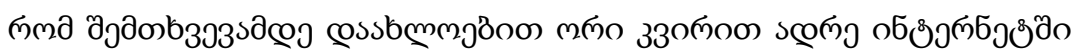

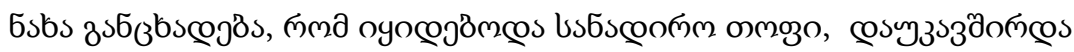

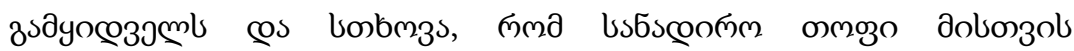

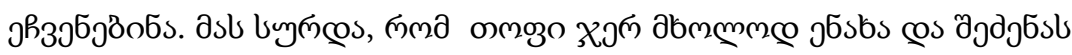

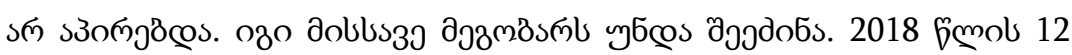

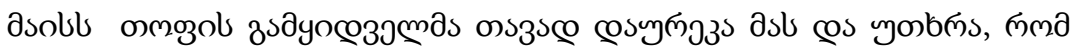

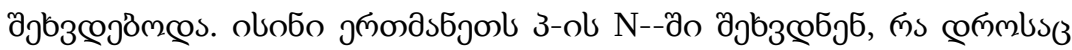

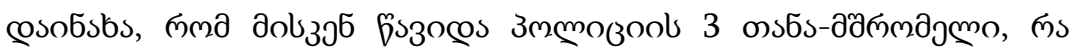

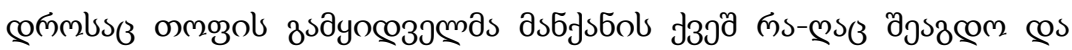

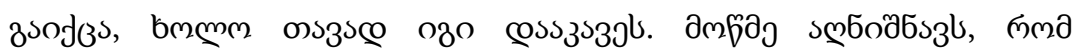

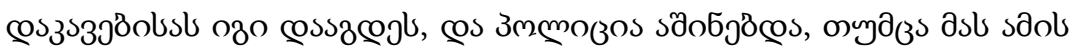

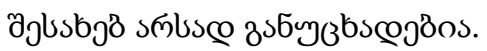

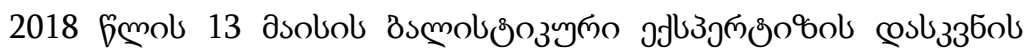

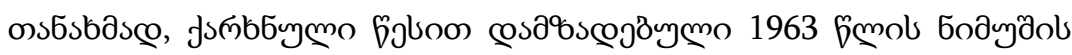

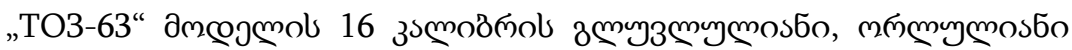

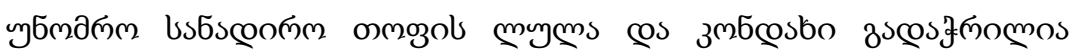

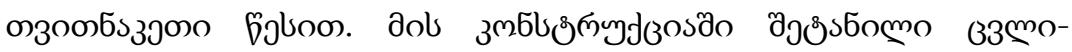

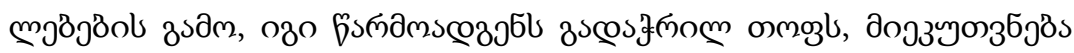

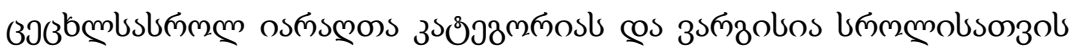

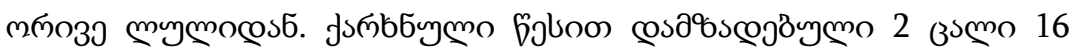

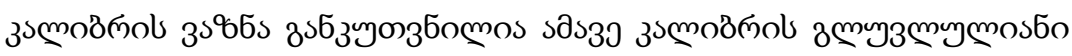

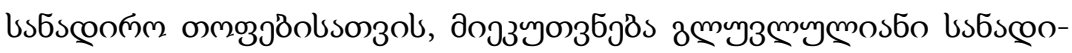




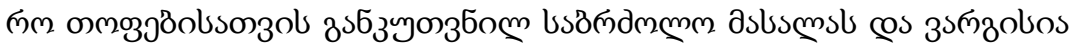

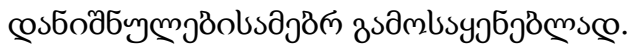

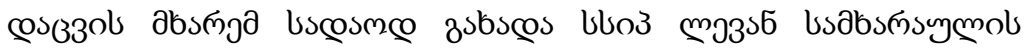

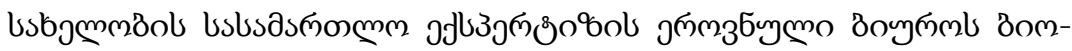

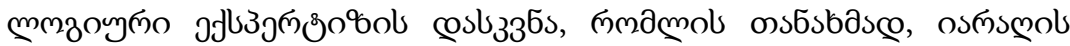

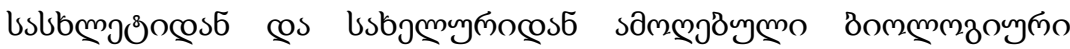

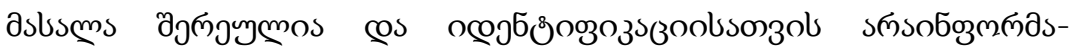

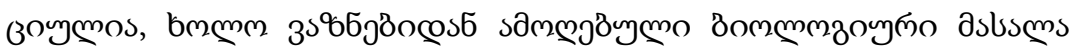

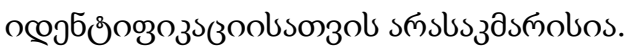

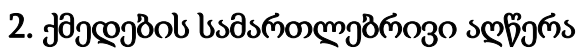

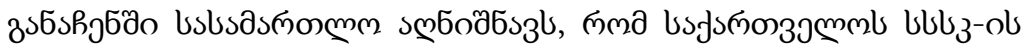

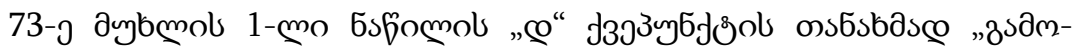

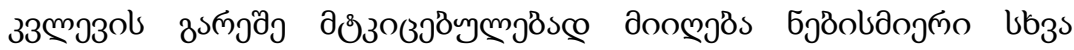

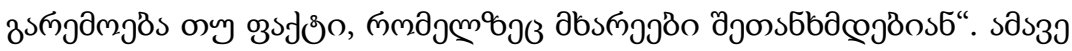

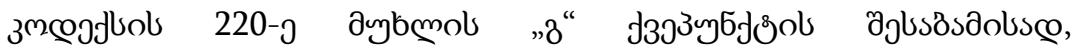

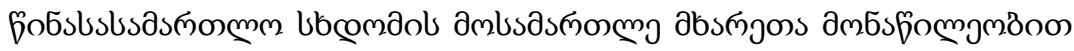

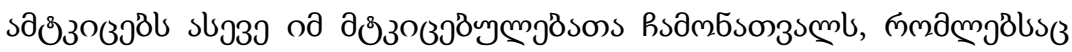

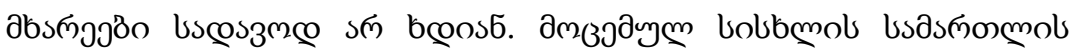

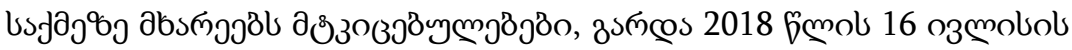

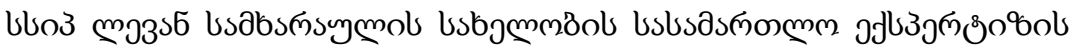

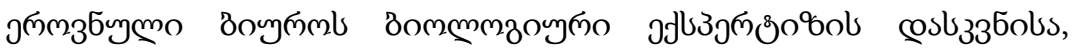

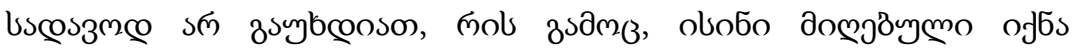

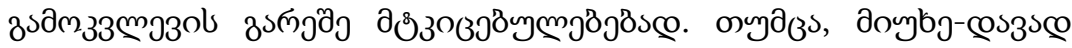

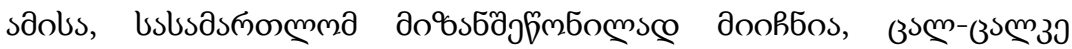

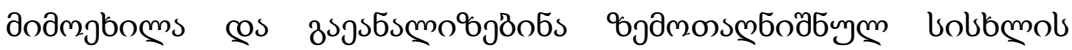

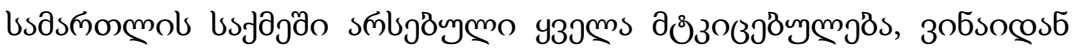

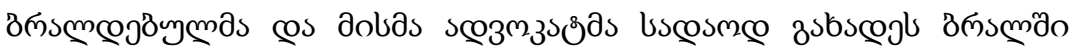

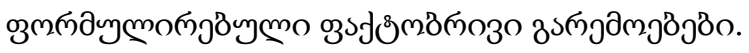

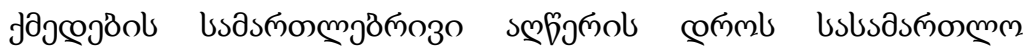

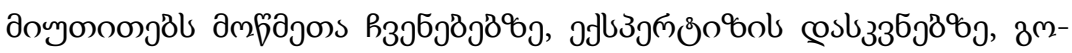




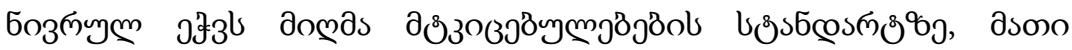

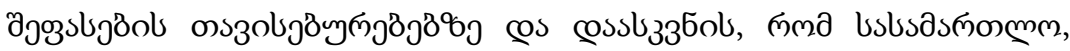

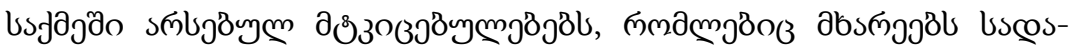

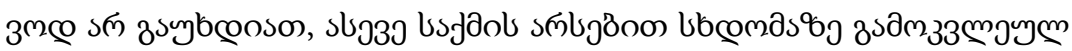

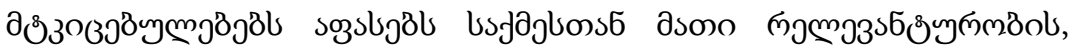

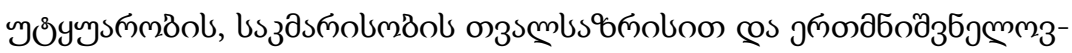

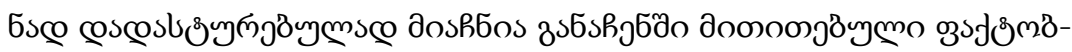

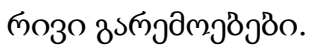

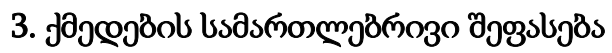

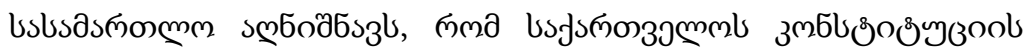

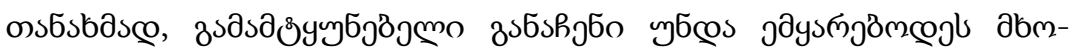

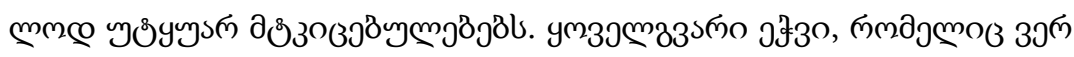

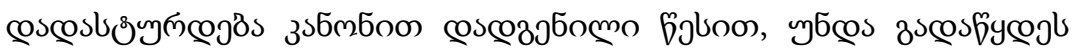

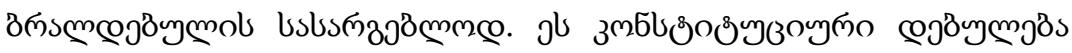

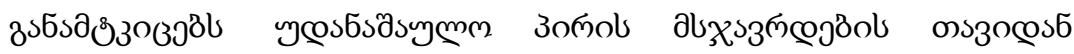

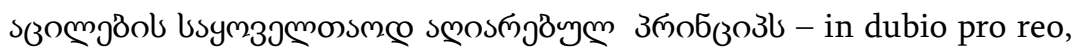

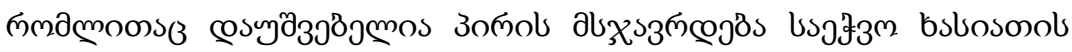

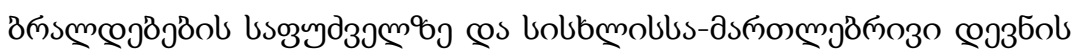

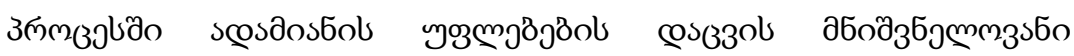

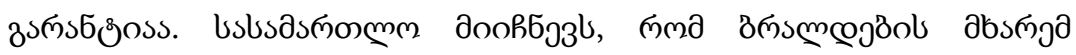

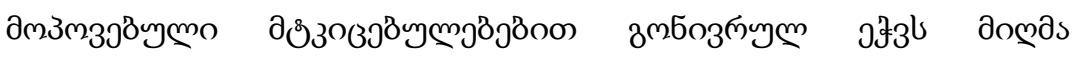

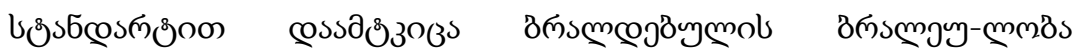

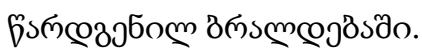

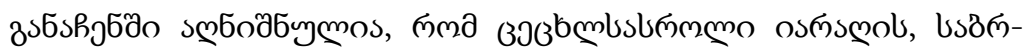

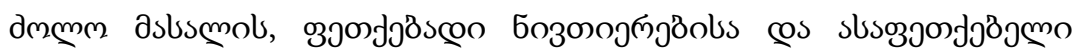

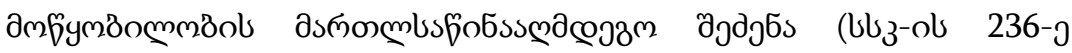

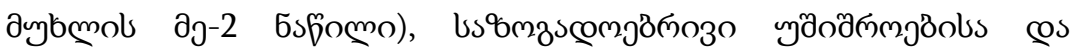

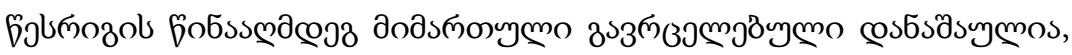

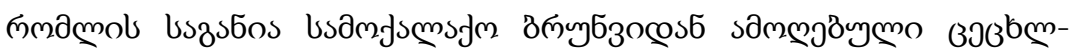

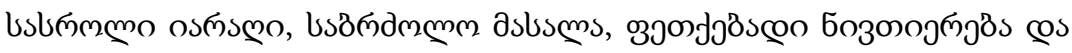




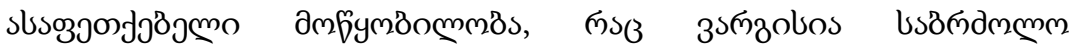

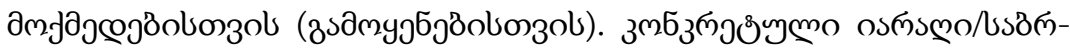

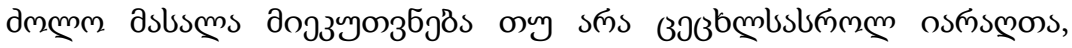

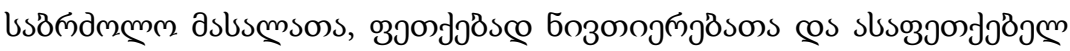

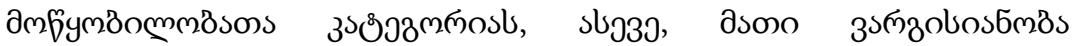

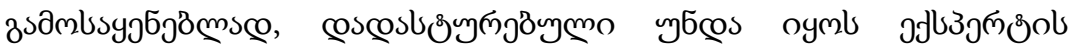

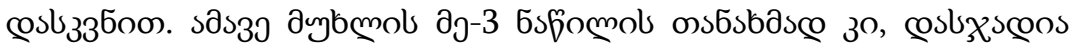

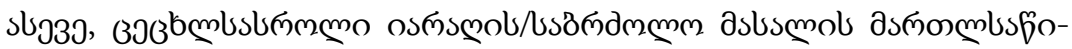

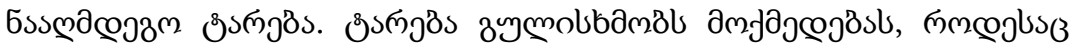

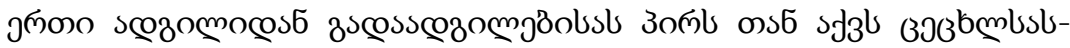

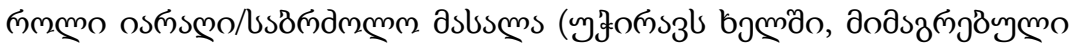

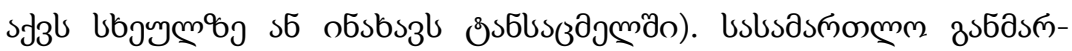

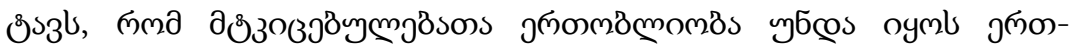

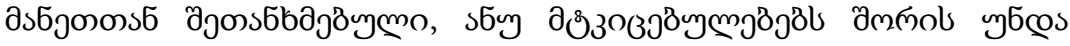

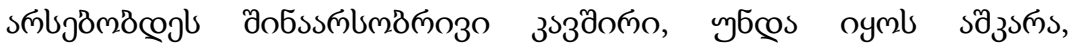

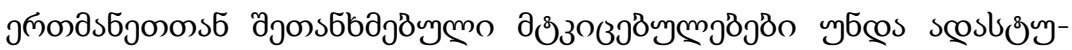

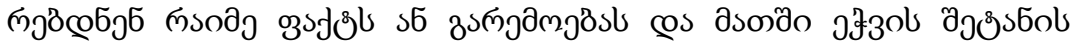

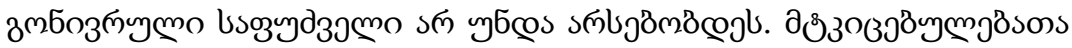

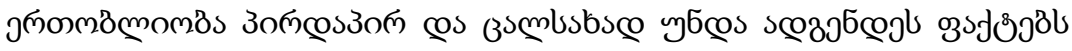

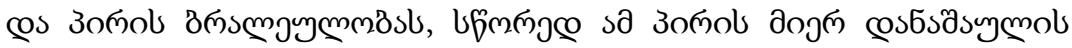

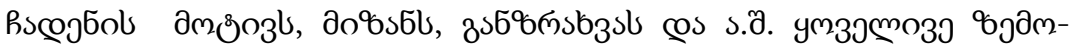

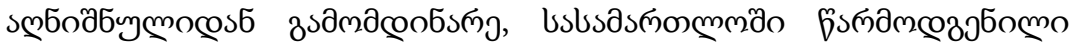

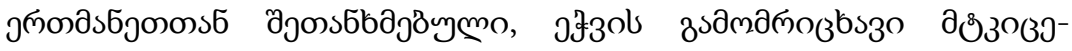

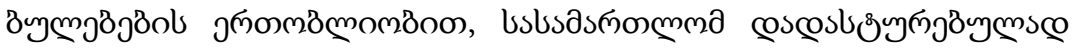

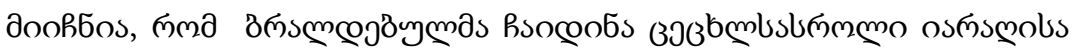

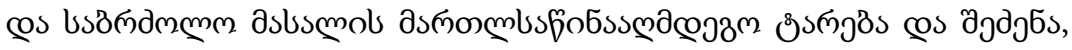

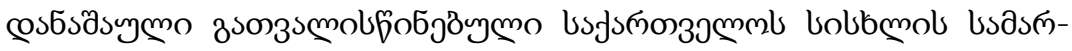

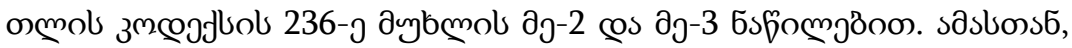

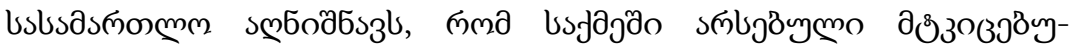

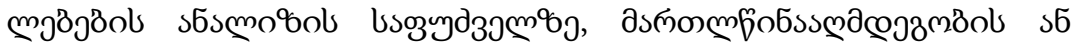

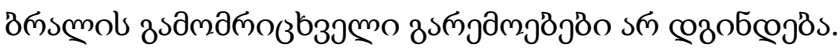




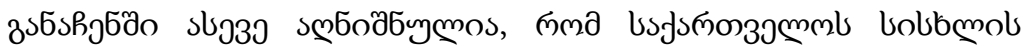

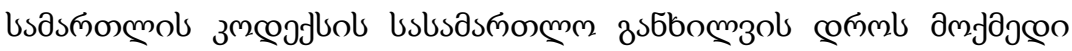

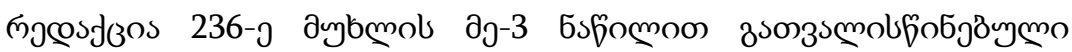
cosbsasymolssozol (вэвb

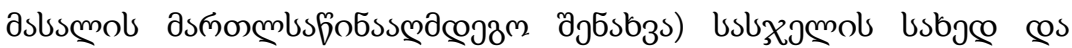

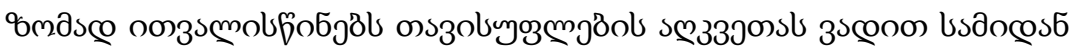

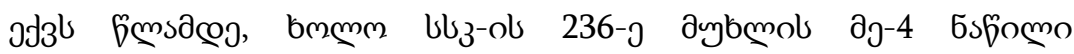

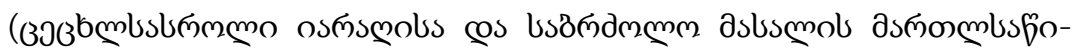

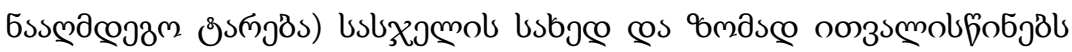

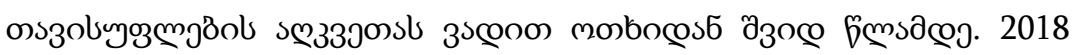

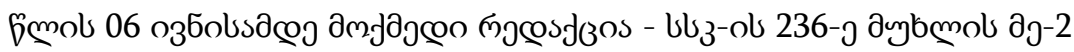

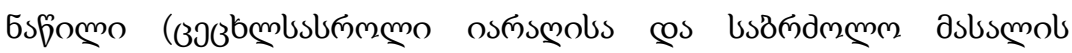

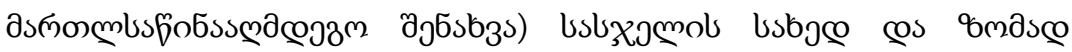

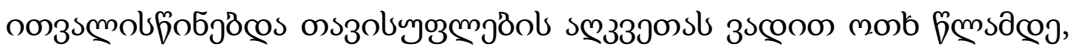

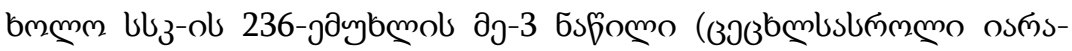

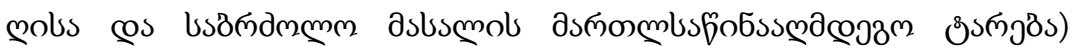

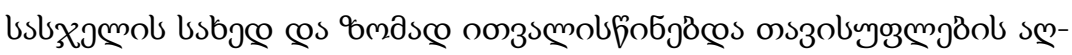

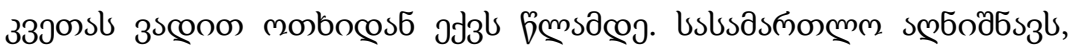

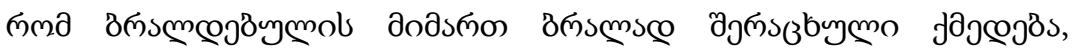

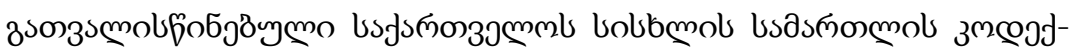

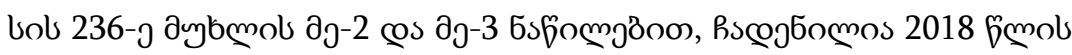

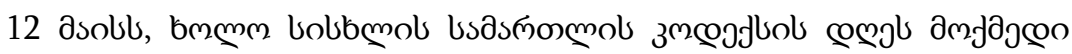

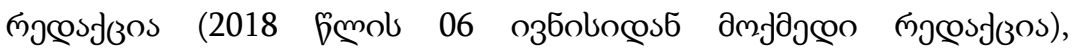

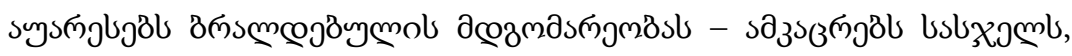

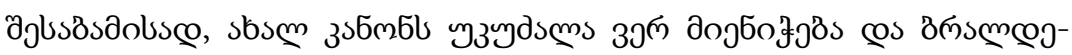

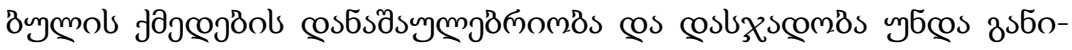

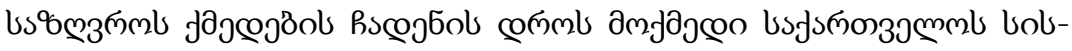

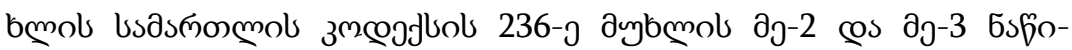

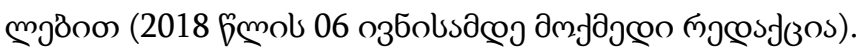

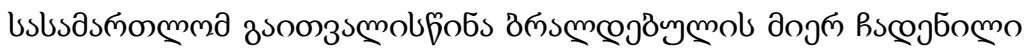

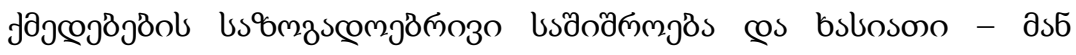




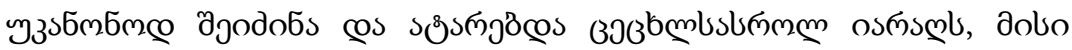

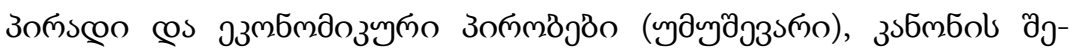

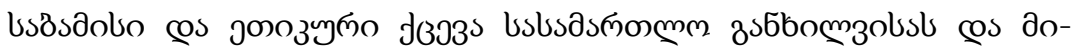

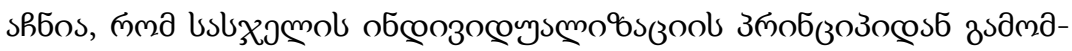

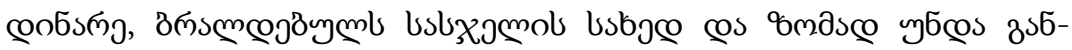

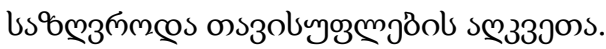

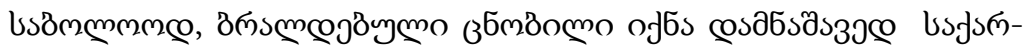

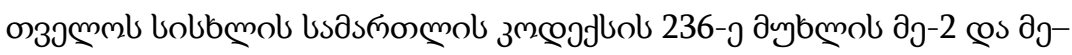

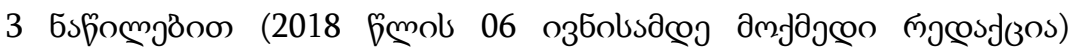

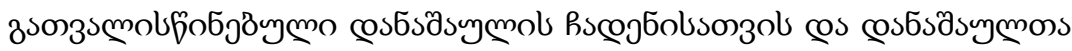

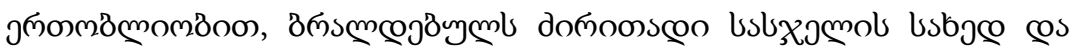

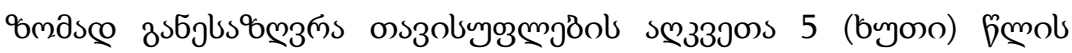

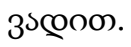

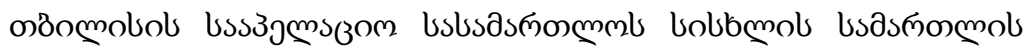

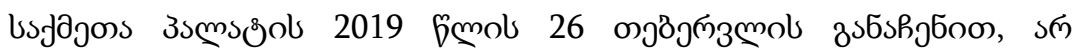

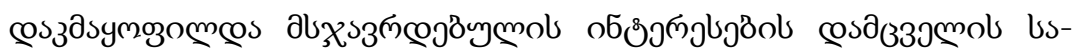

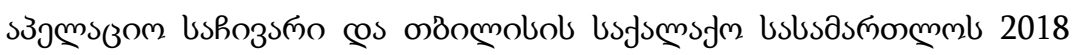

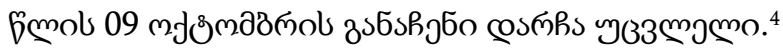

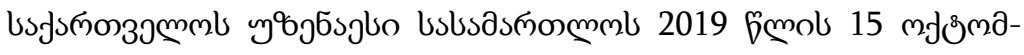

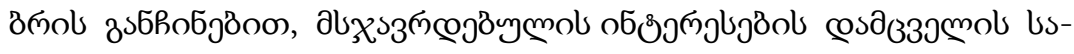

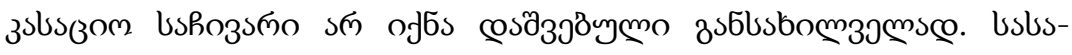

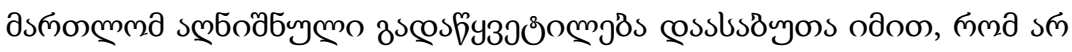

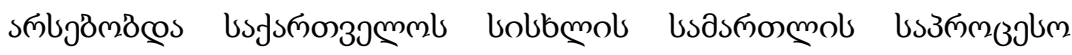

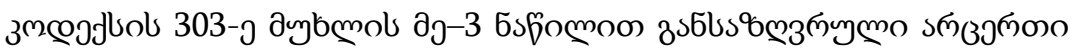
usogyd 3 mलо. ${ }^{5}$

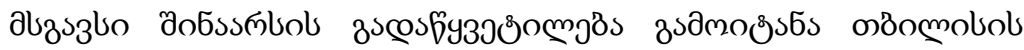

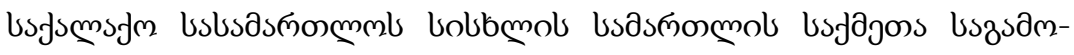

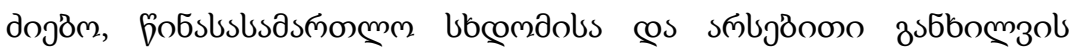

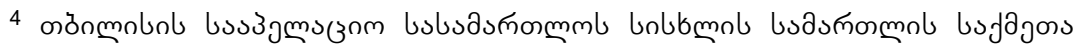

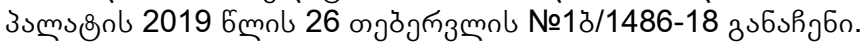

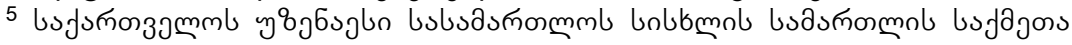

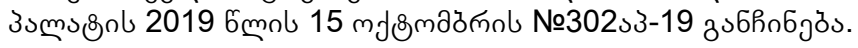




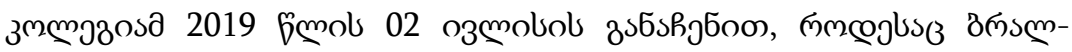

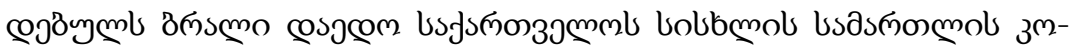

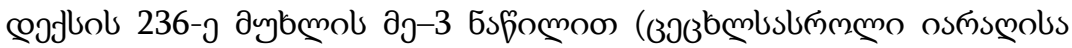

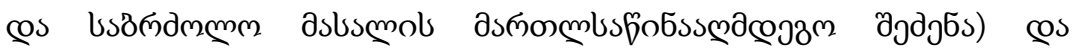

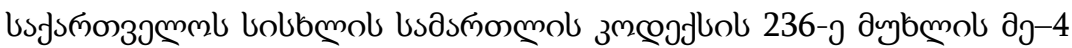

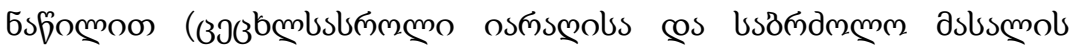

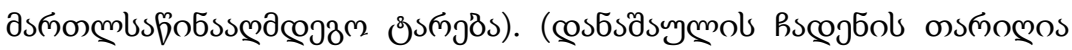

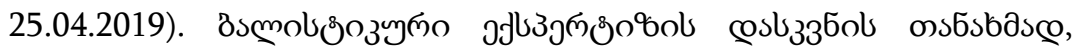

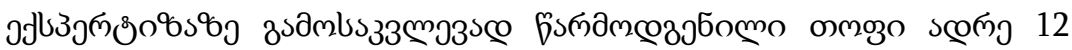

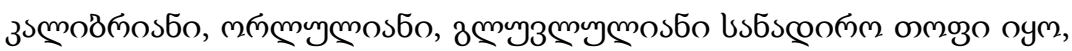

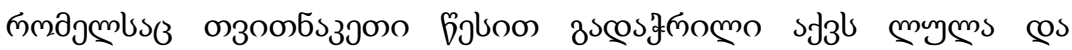

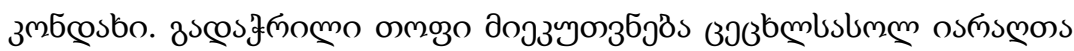

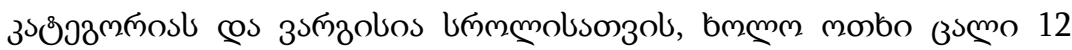

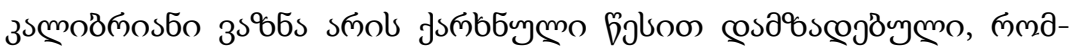

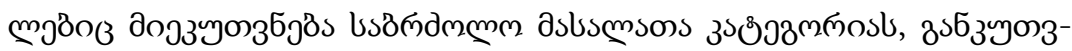

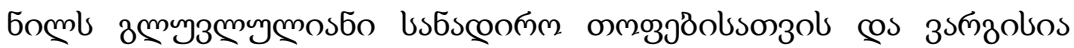

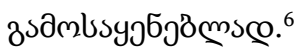

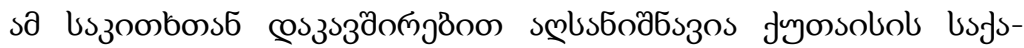

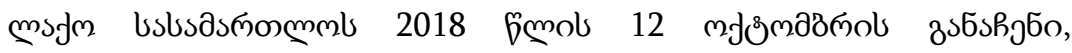

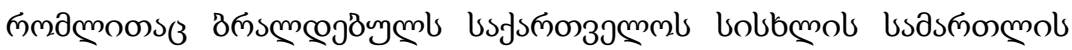

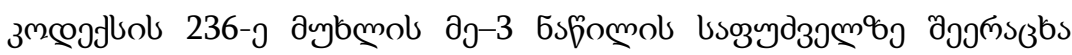

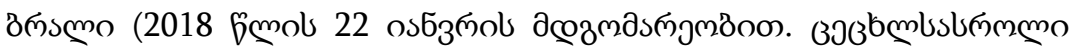

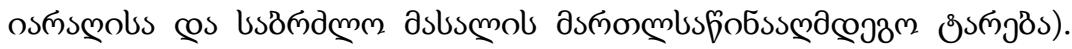

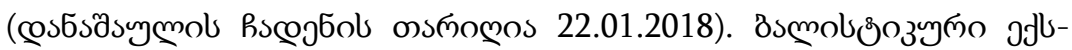

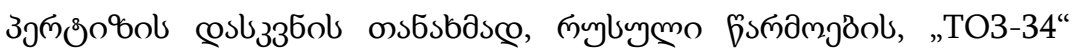

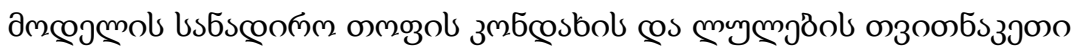

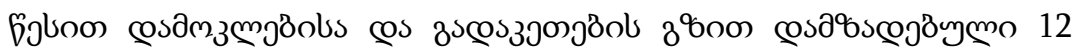

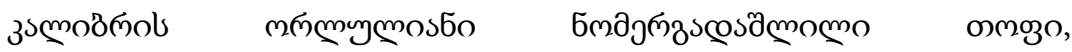

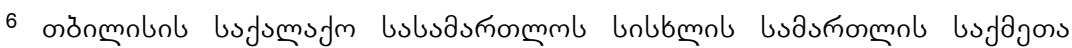

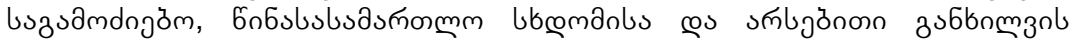

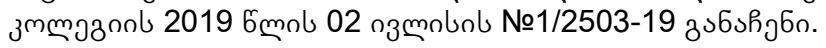




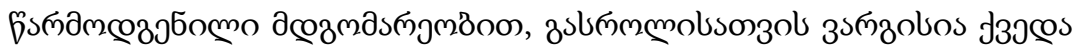

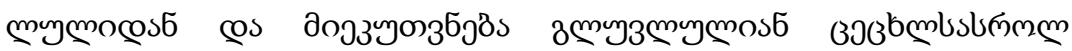

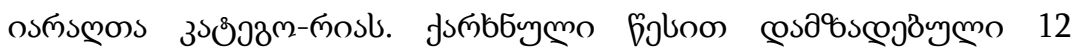

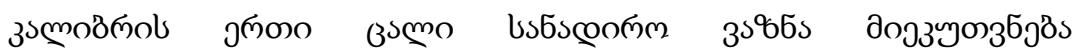

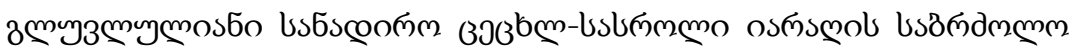
astuscusls. ${ }^{7}$

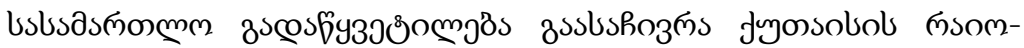

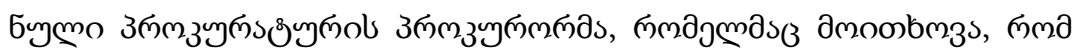

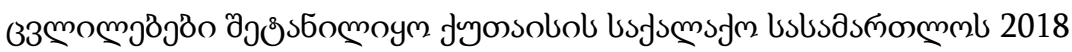

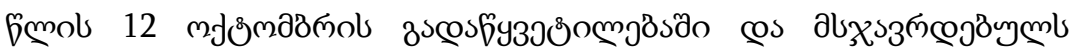

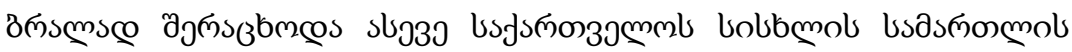

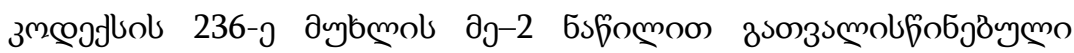

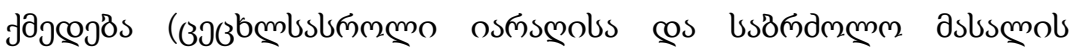

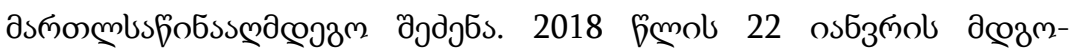

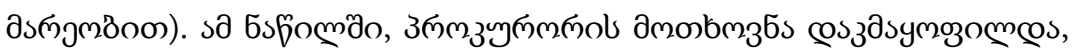

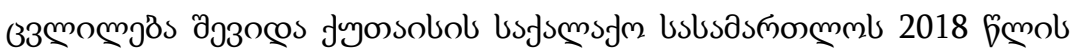

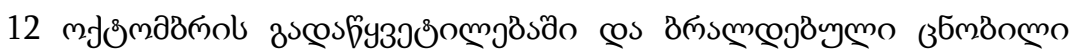

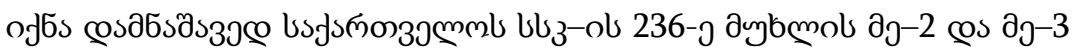

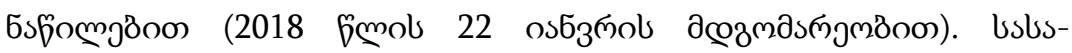

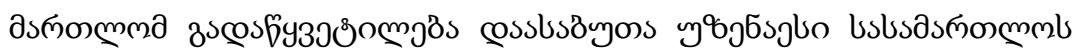

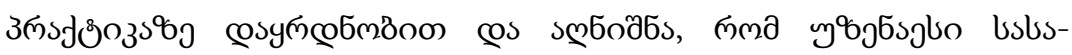

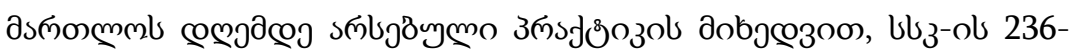

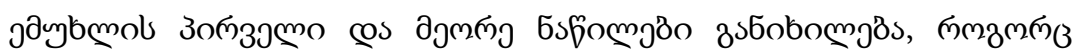

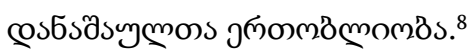

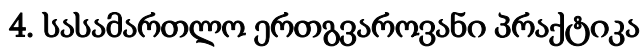

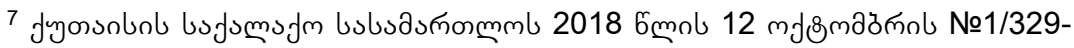
18 zuбshjбo.

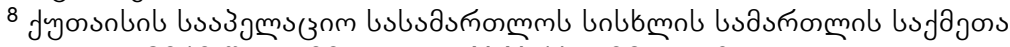

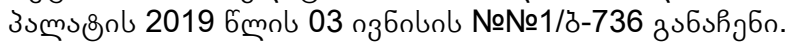




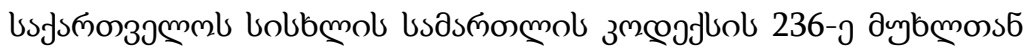

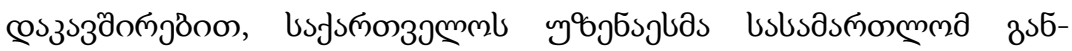

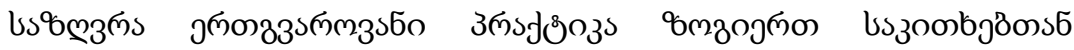

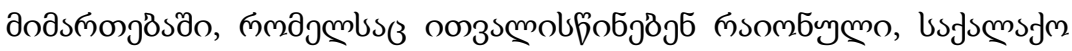

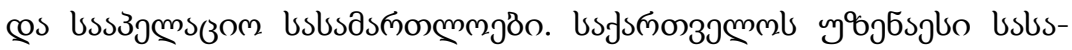

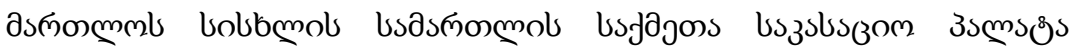

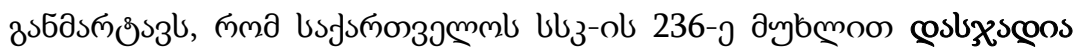

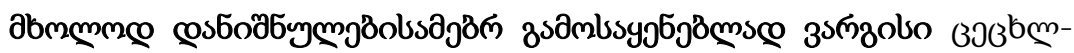

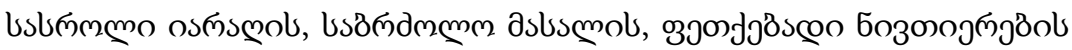

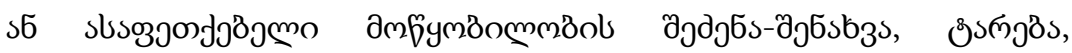

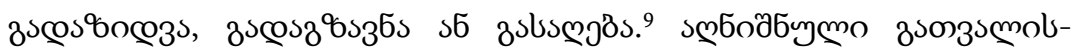

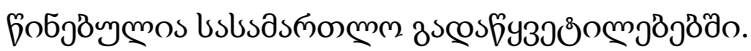

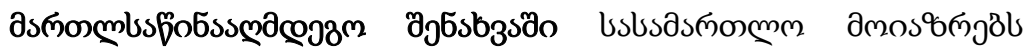

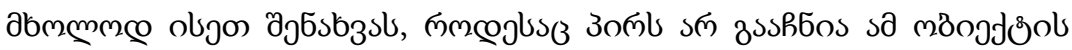

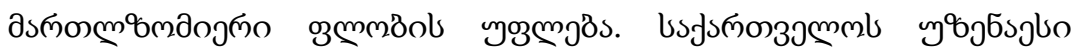

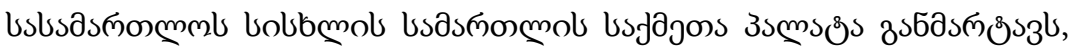

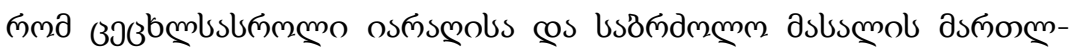

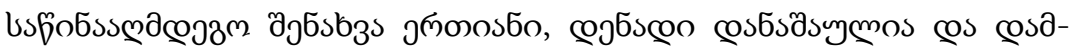

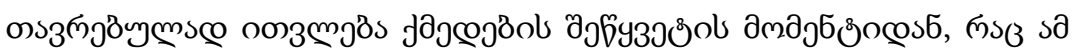

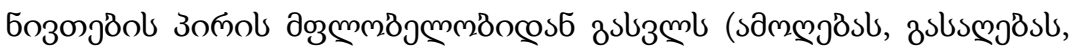

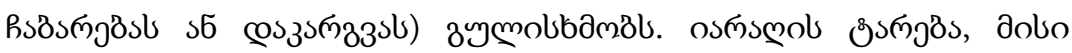

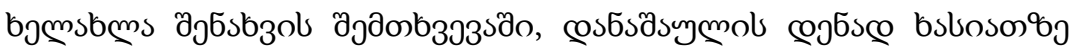

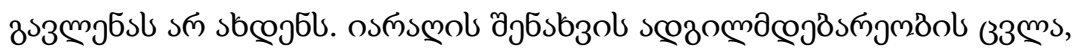

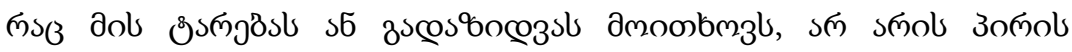

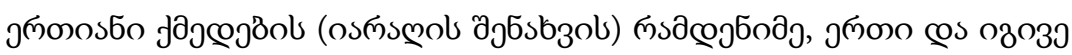

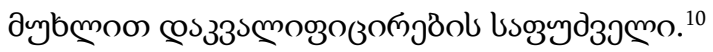

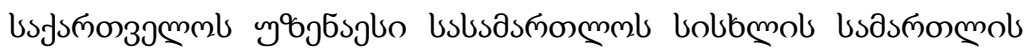

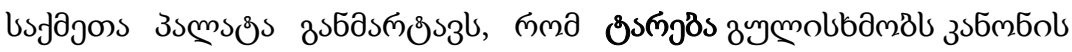

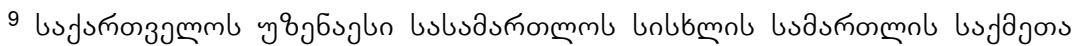

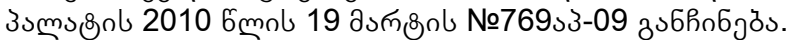

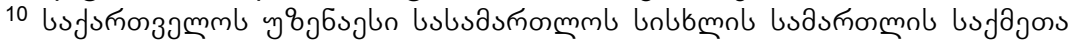

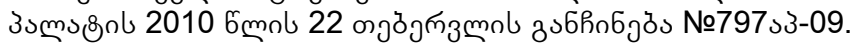




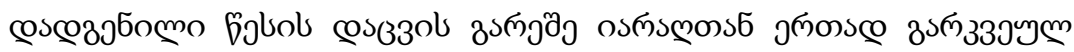

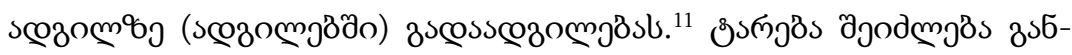

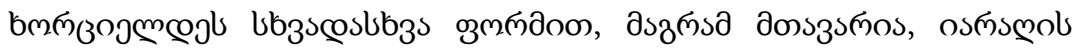

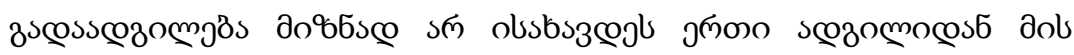

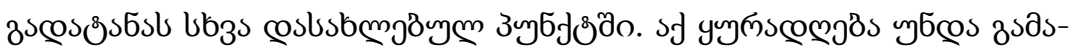

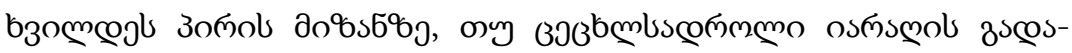

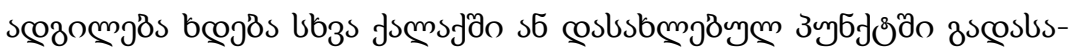

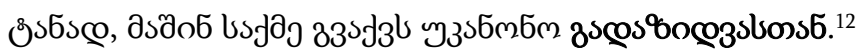

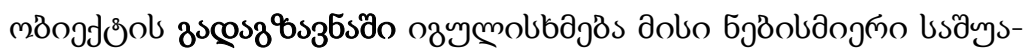

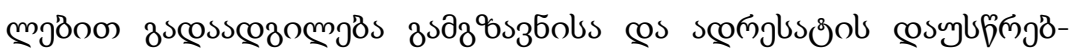

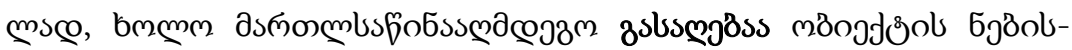

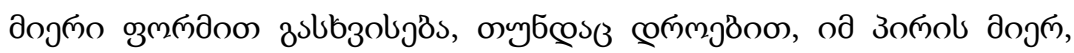

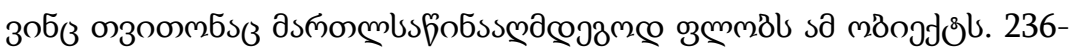

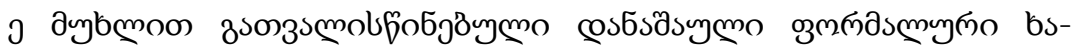
bosonobss cos cosansz'

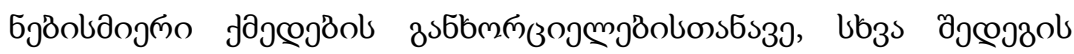

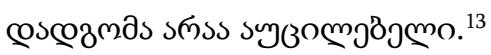

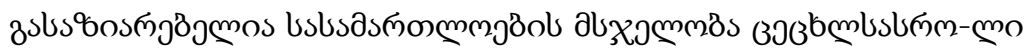

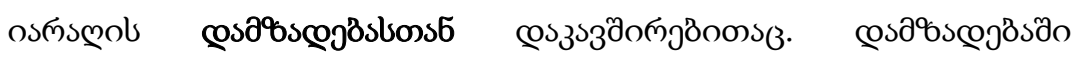

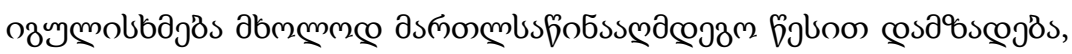

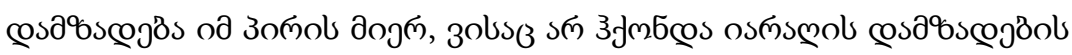

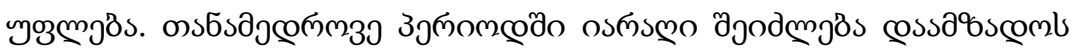

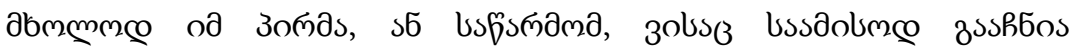

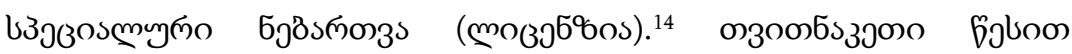

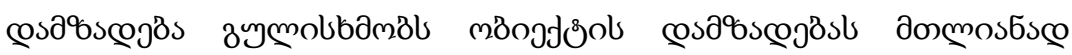

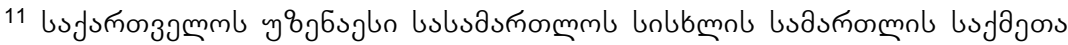

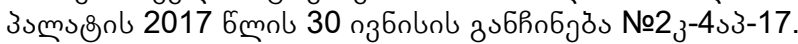

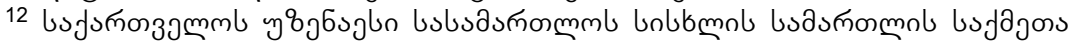

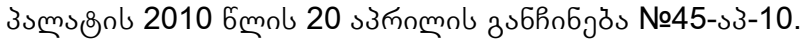

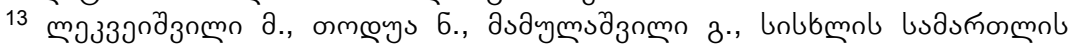

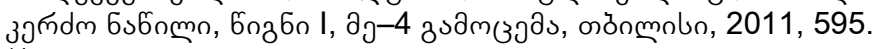

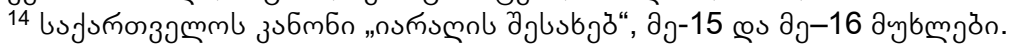




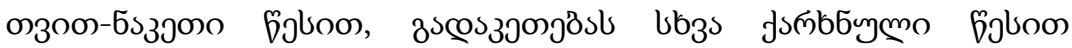

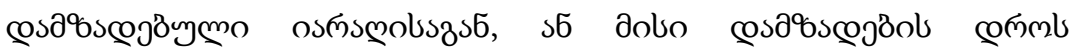

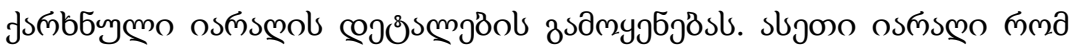

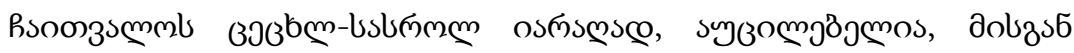

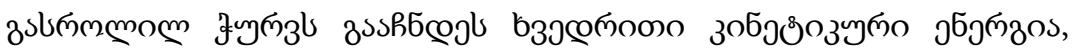

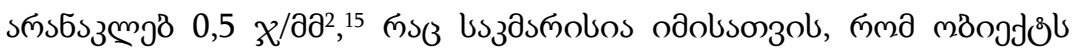

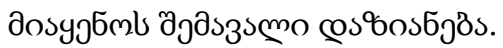

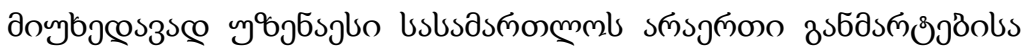

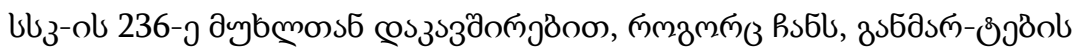

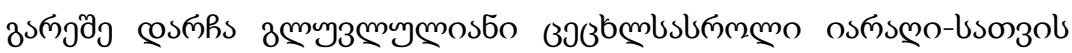

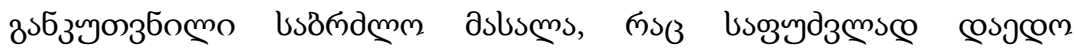

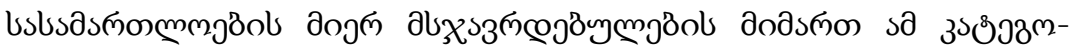

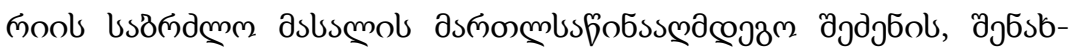

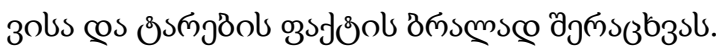

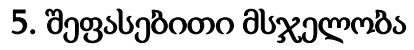

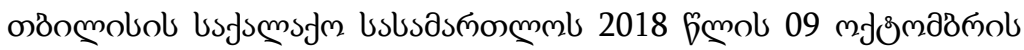

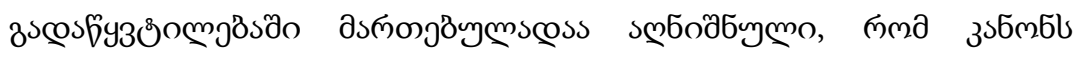

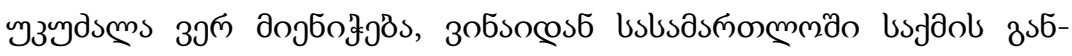

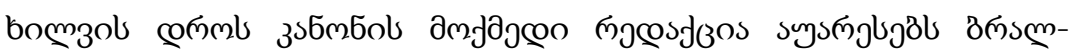

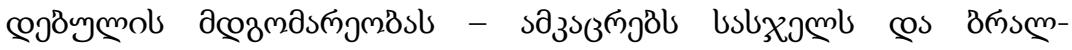

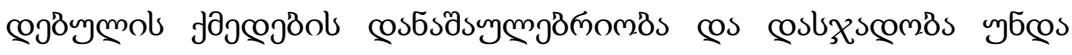

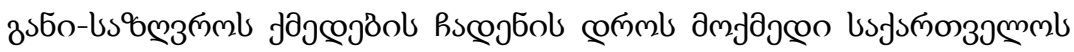

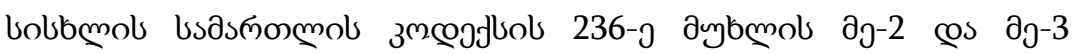

\footnotetext{
15 Методика решения вопросов о принадлежности обьектов к ручному стрелковому огнестрельному оружию, их исправности и пригодности к стрельбе, Утверждена межведомственным научно-методическим советом в области судебной экспертизы при межведомственной комиссии по вопросам судебно-экспертной деятельности при совете безопасности республики Беларусь, Беларусь, 25.06.2008, Протокол № $5,7$.
} 


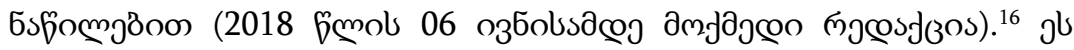

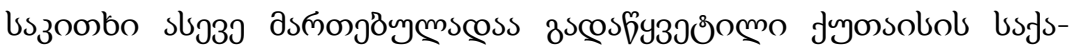

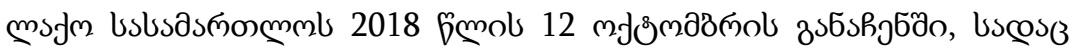

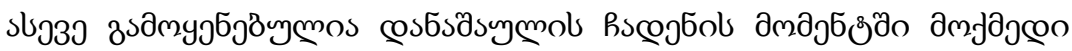

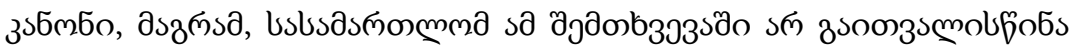

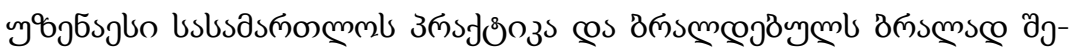

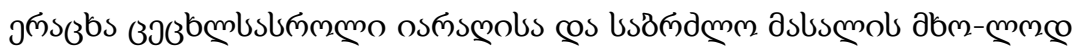

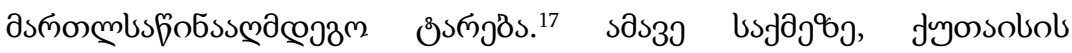

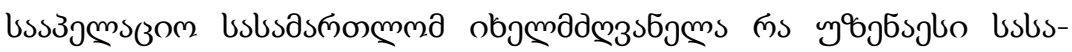

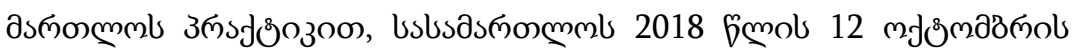

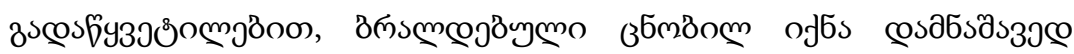

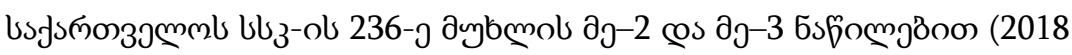

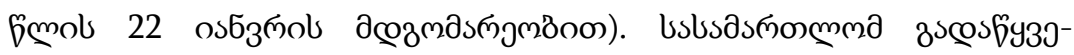

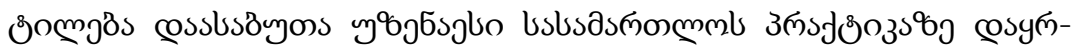

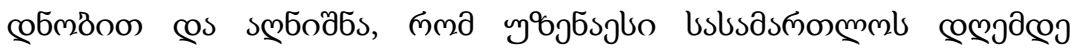

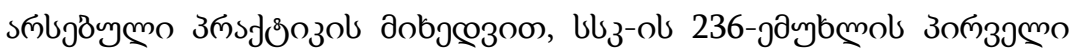

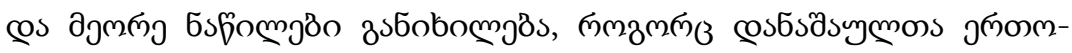

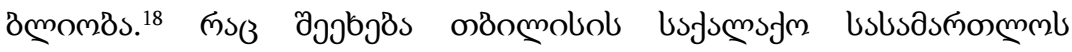

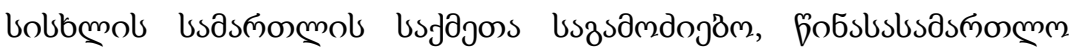

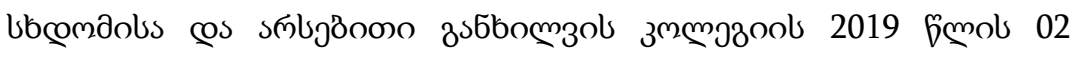

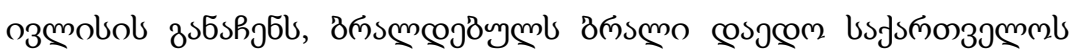

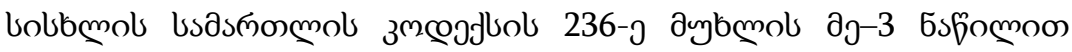

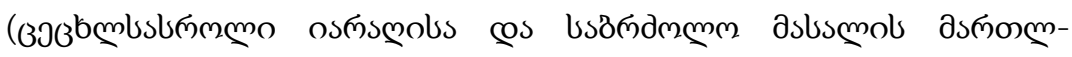

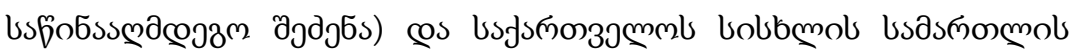

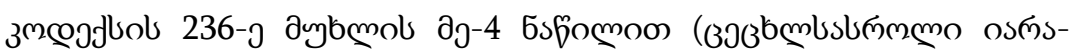

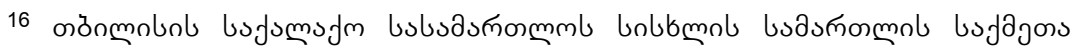

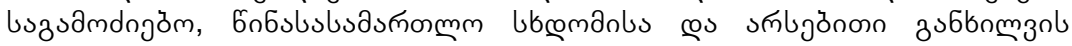

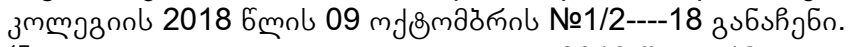

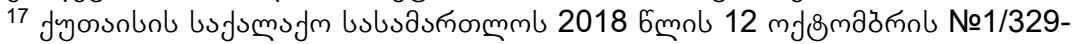
18 zuбshg6n.

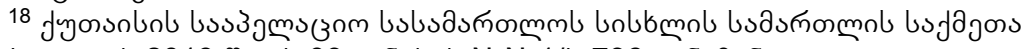

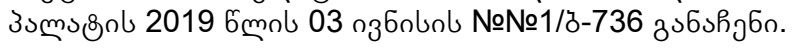




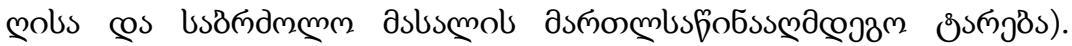

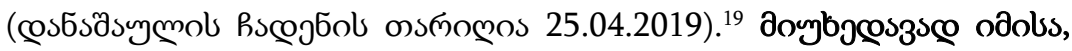

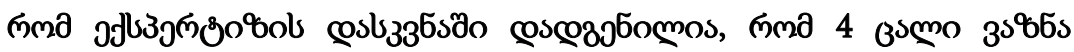

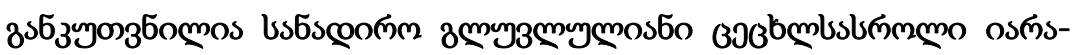

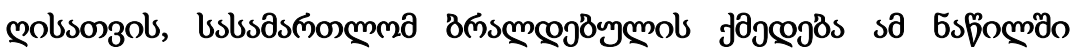

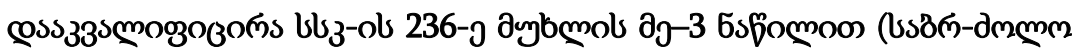

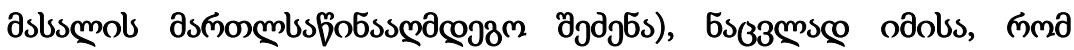

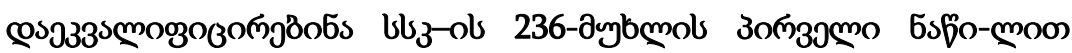

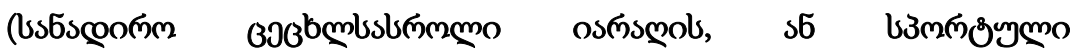

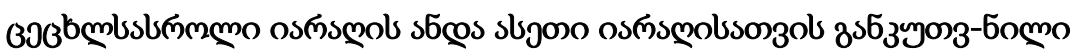

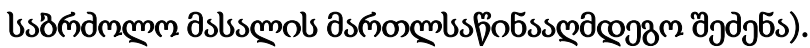

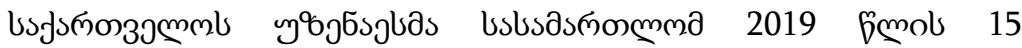

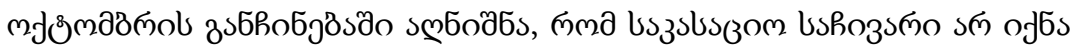

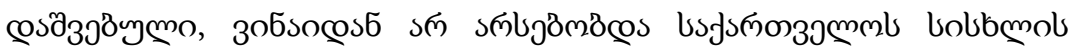

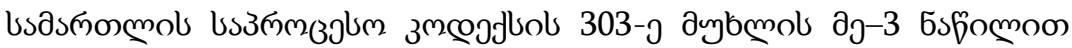

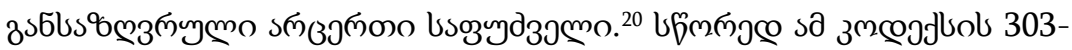

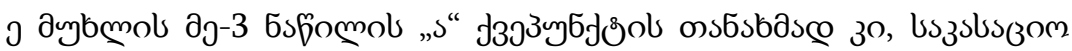

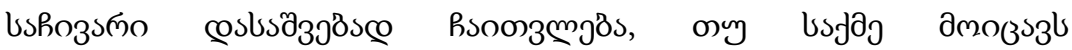

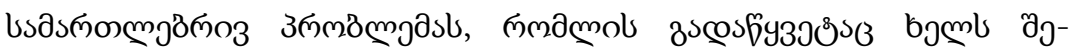

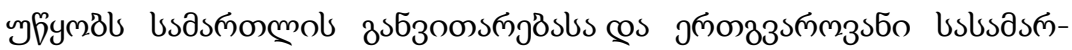

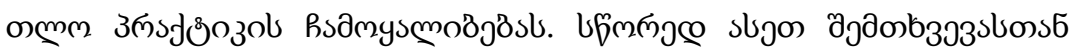

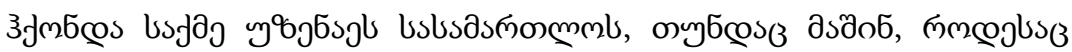

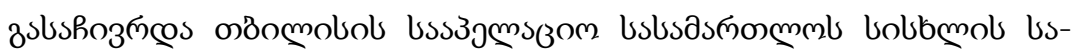

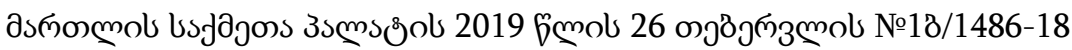

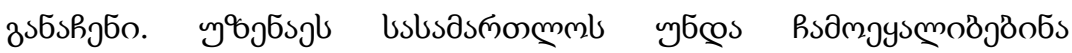

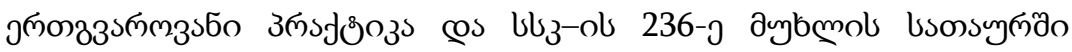

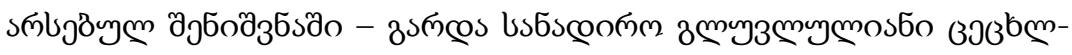

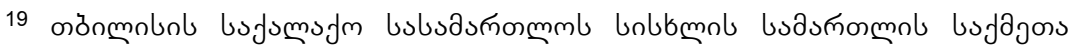

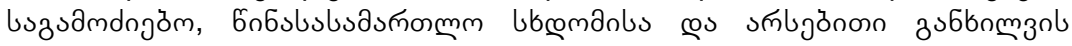

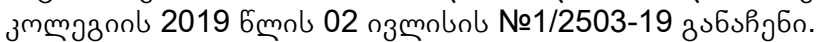

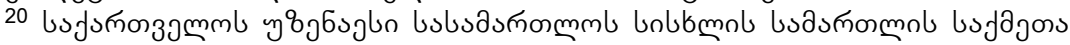

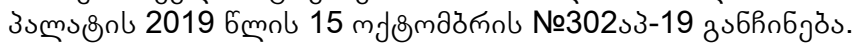




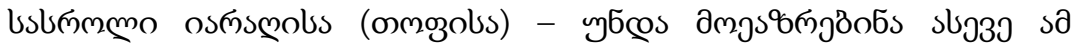

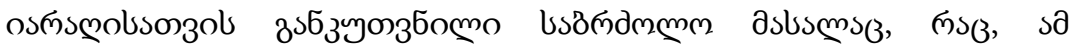

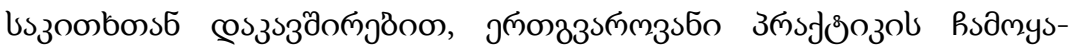

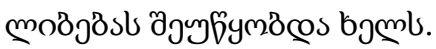

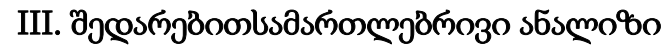

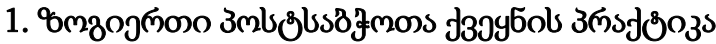

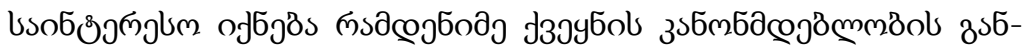

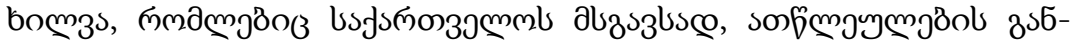

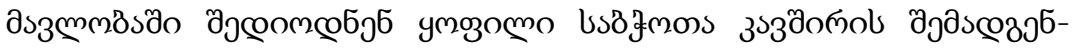

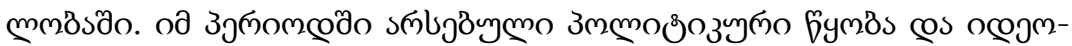

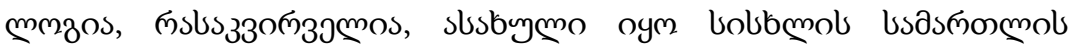

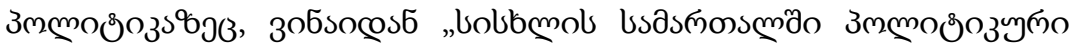

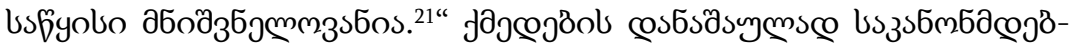

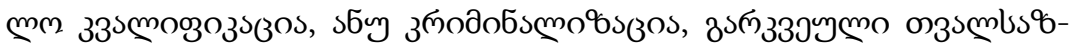

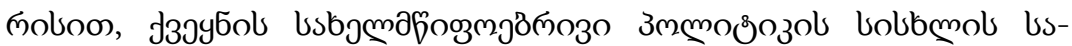

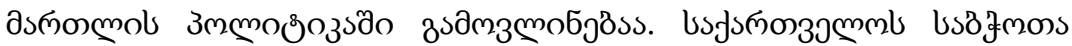

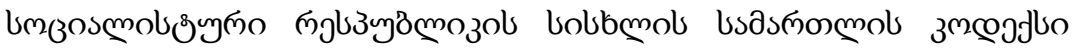

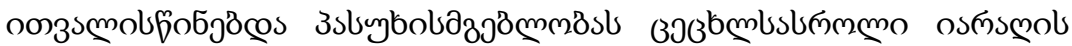

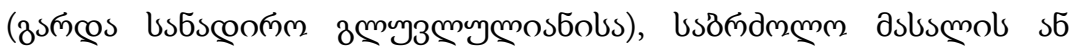

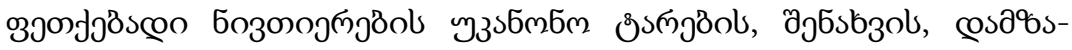

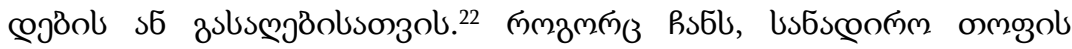
3

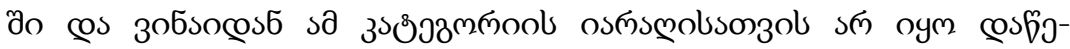

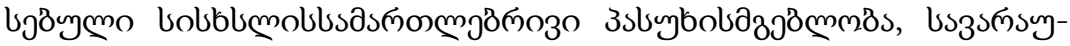

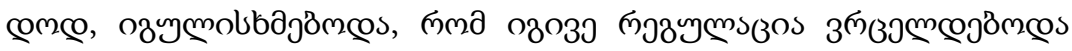

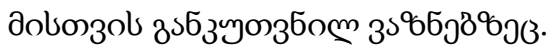

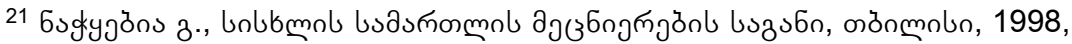
132.

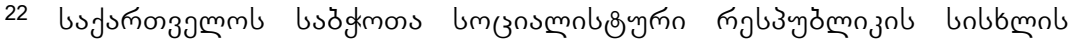

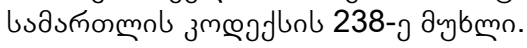




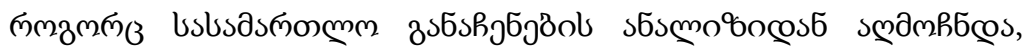

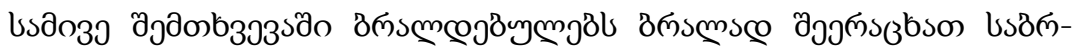

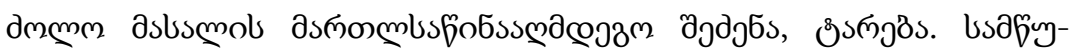

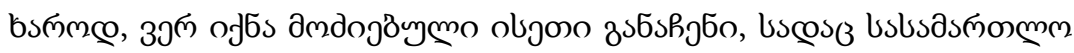

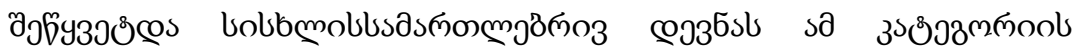
3s

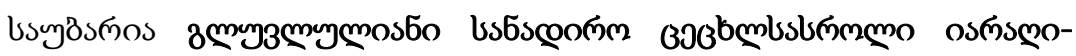

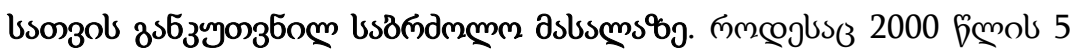

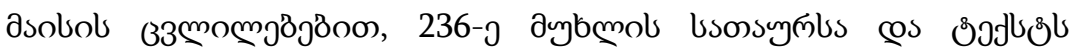

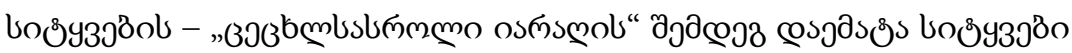

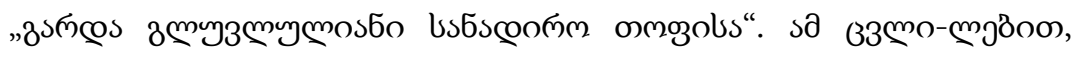

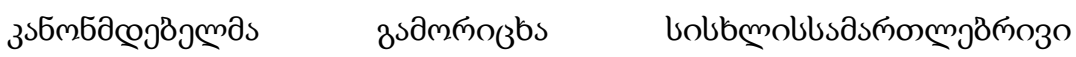

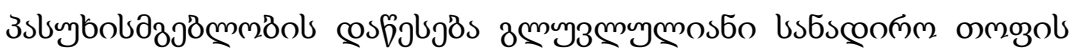

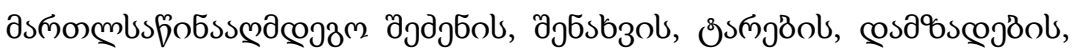

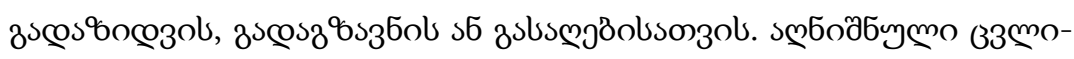

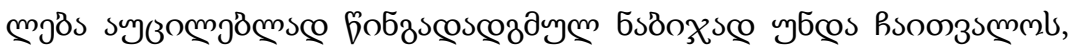

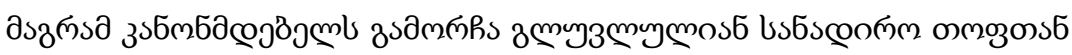

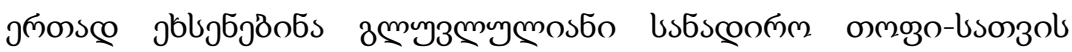

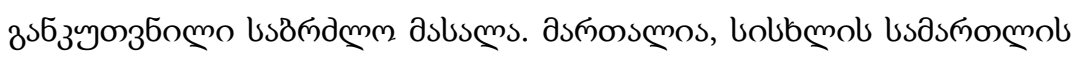

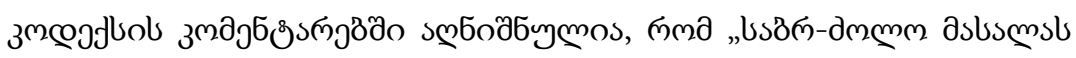

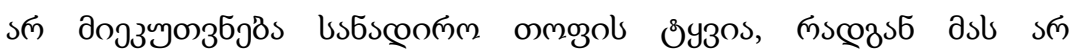

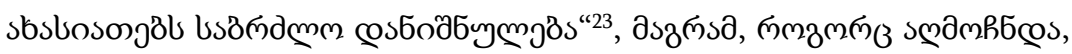

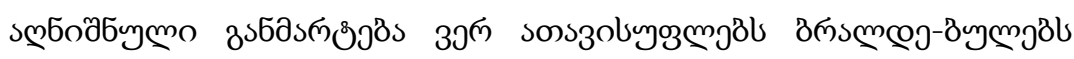

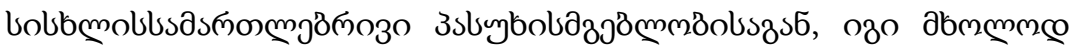

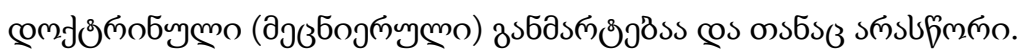

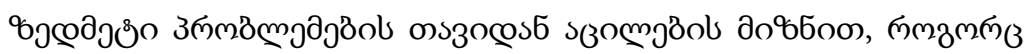

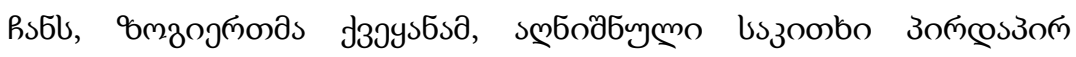

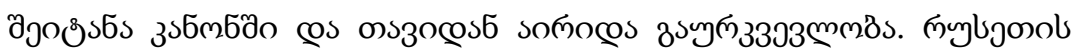

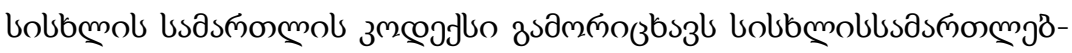

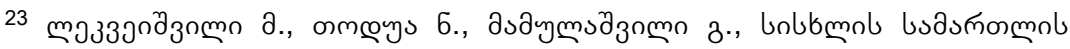

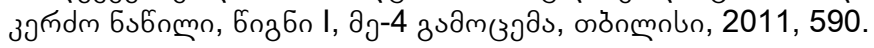




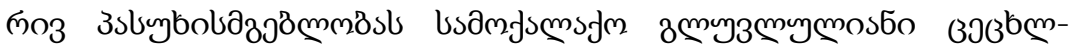

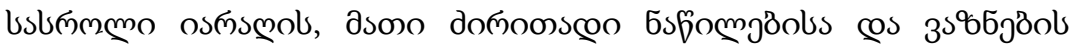

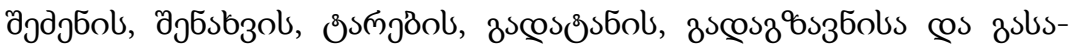

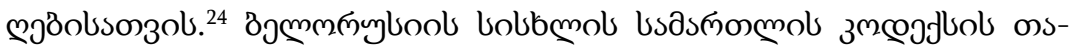

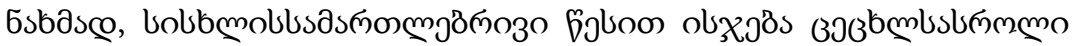

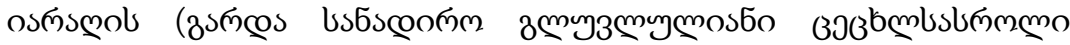

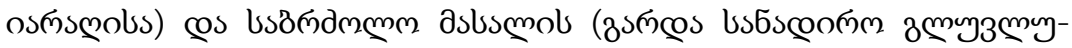

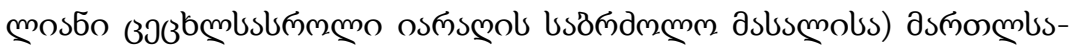

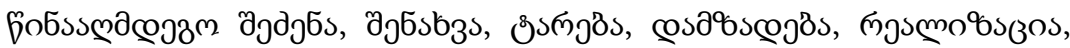

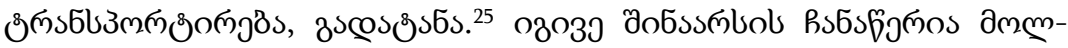

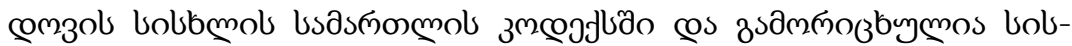

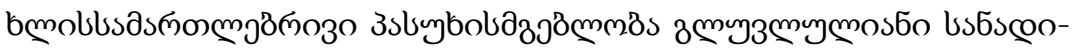

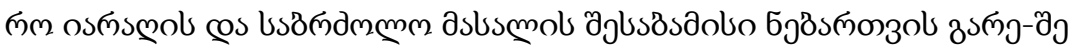

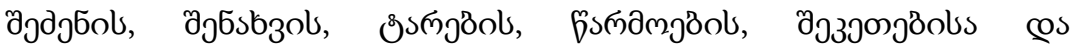
zsubzoljgöobsonzol. ${ }^{26}$

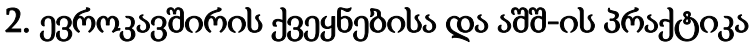

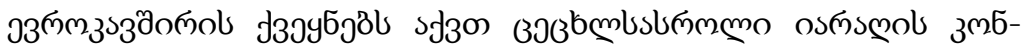

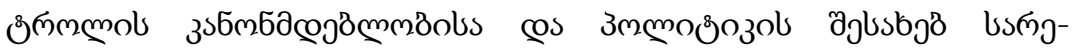

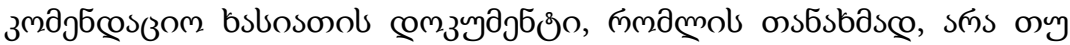

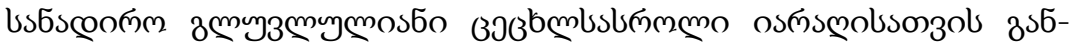

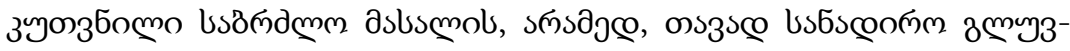

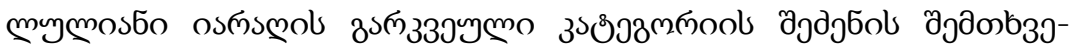

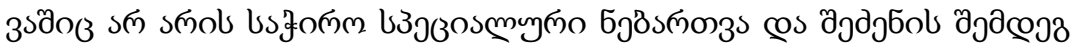

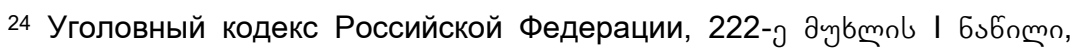

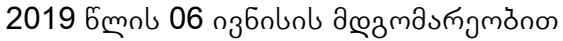

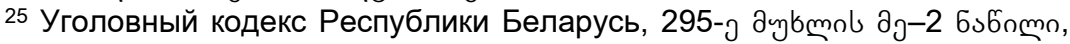
2019 6mol 09 nzmolnb ạamaśrgmỏnon

26 Criminal Code of the Republic of Moldova, 290-

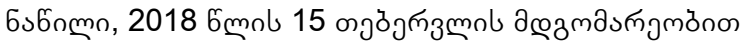




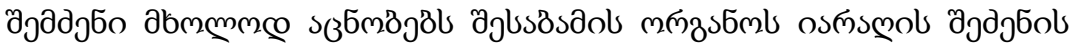

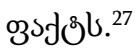

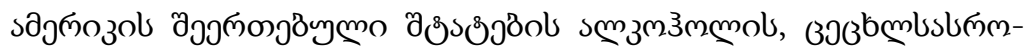

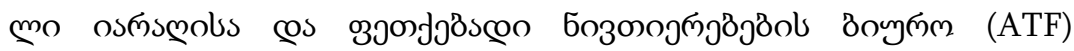

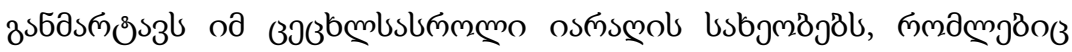

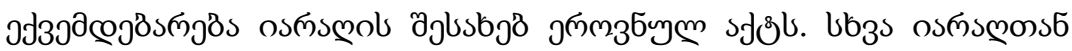

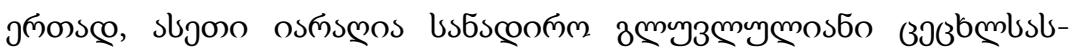

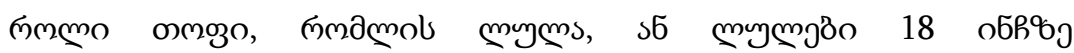

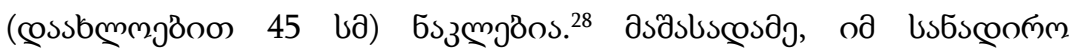

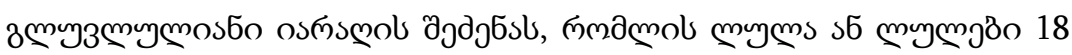

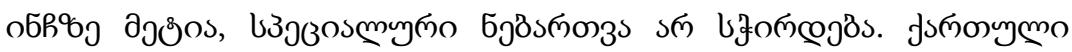

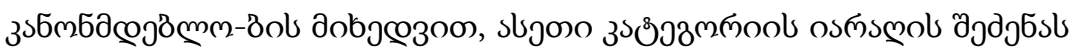

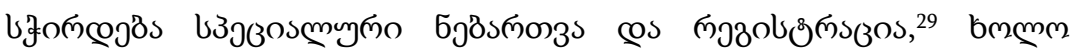

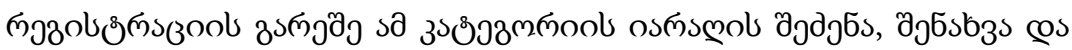

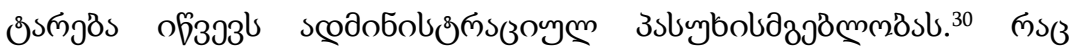

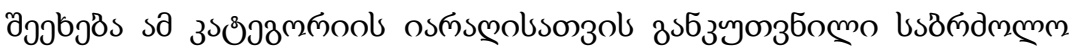

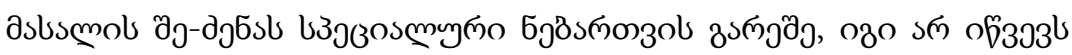

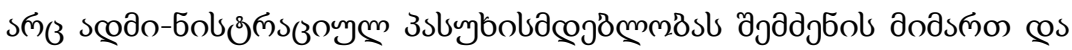

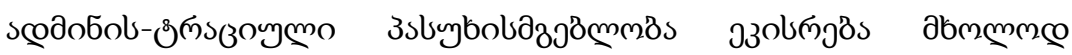

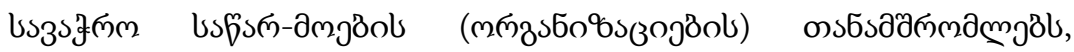

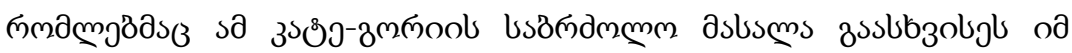

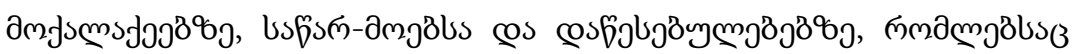

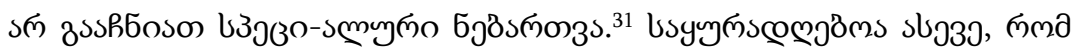

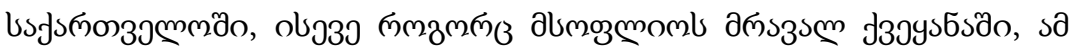

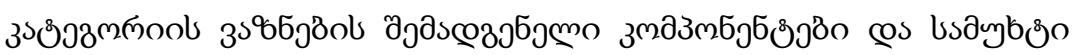

27 Firearms-Control Legislation and Policy: European Union, $<$ https://www.loc.gov/law/help/firearms-control/eu.php>

28 National firearms Act Handbook, U.S. Department of Justice, Bureau of Alcohol, Firearms and Explosives, ATF E-Publication, 2009, 5.

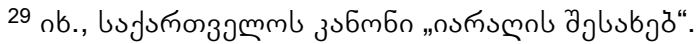

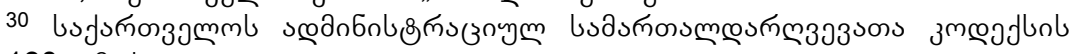
180-э aybmo.

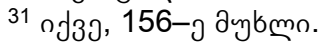


дмбу

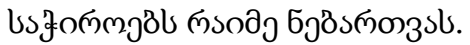

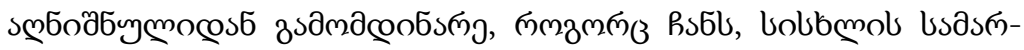

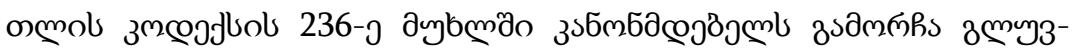

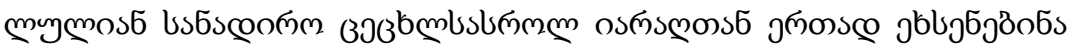

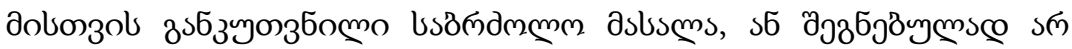

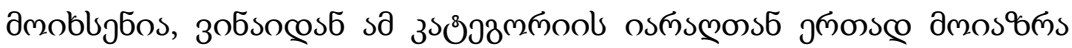

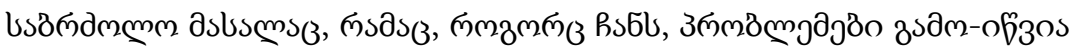

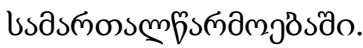

\section{IV. costs336s}

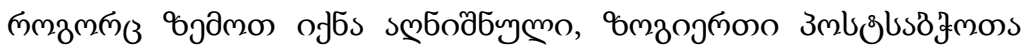

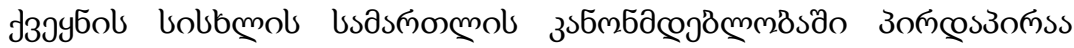

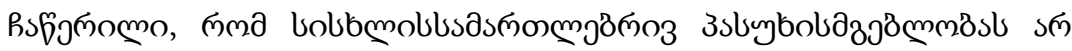

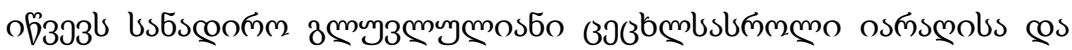

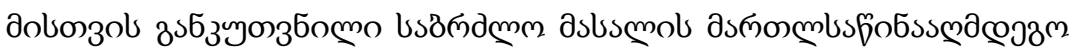

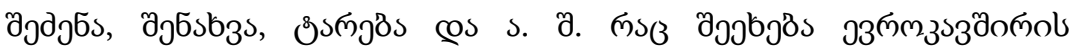

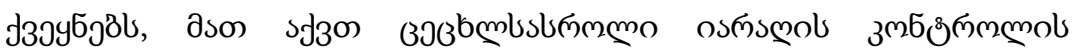

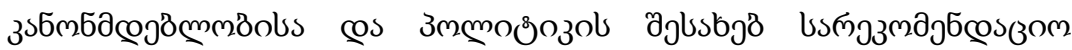

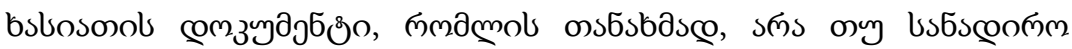

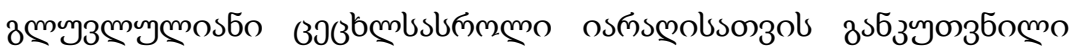

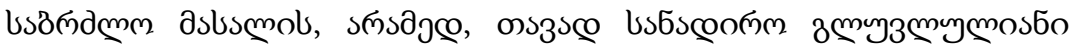

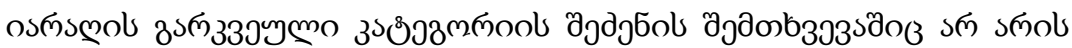

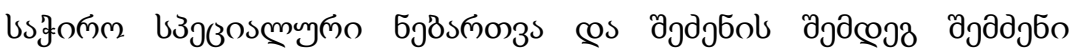

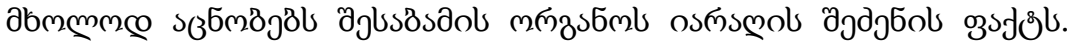

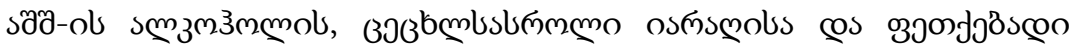

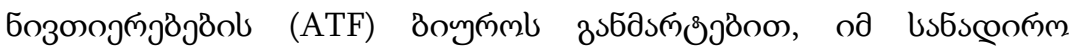

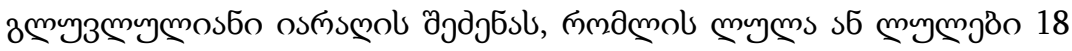

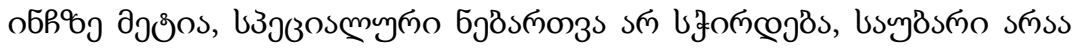

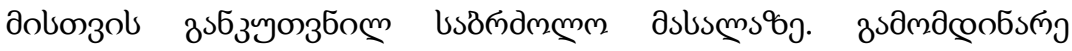




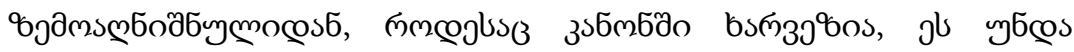

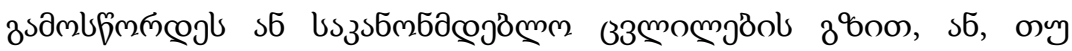

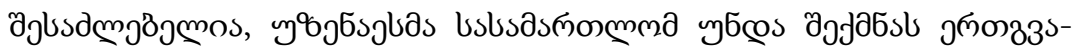

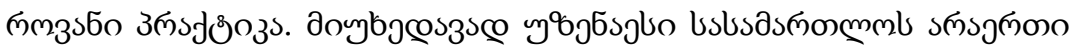

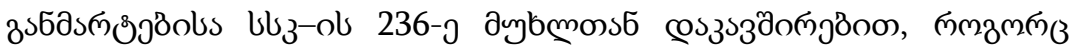

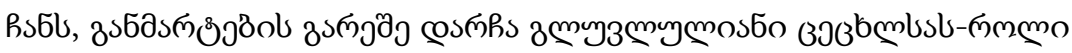

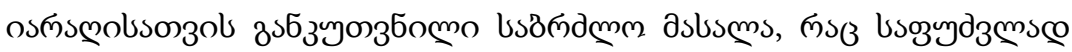

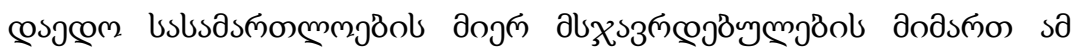

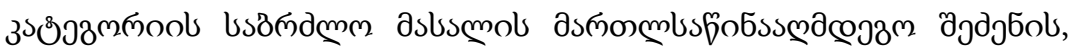

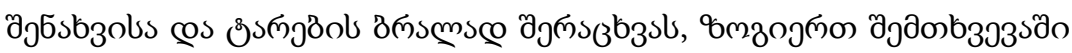

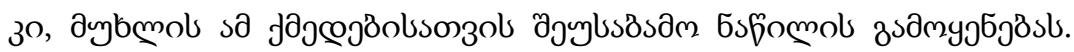

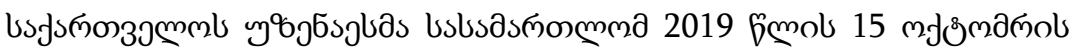

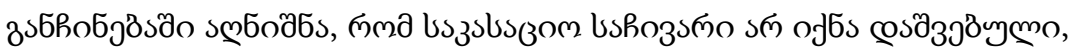

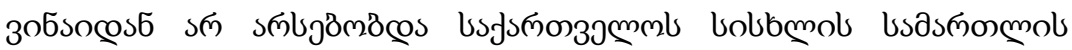

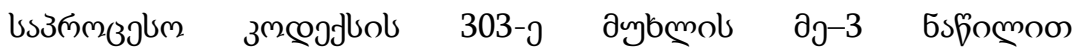

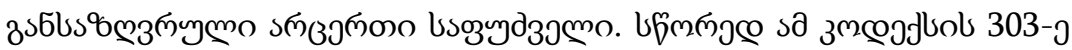

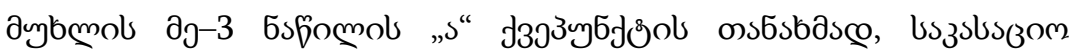

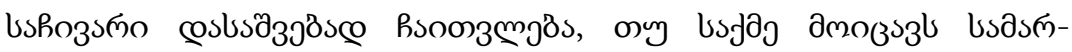

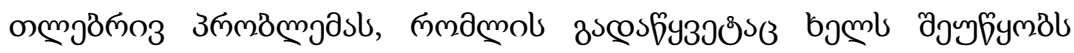

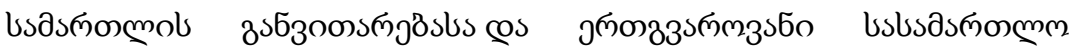

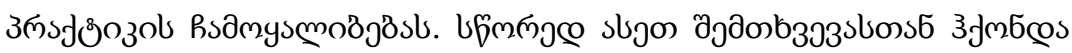

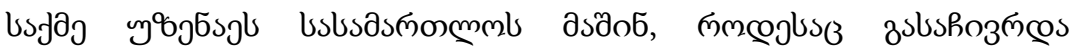

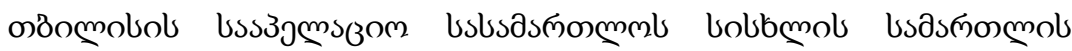

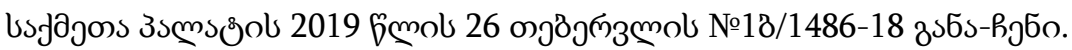

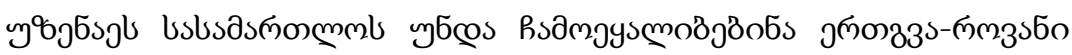

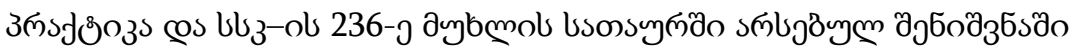

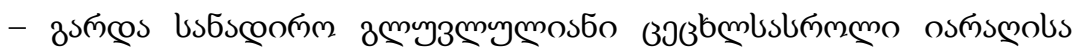

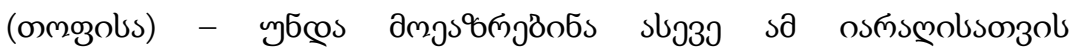

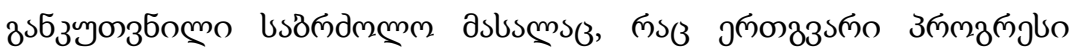

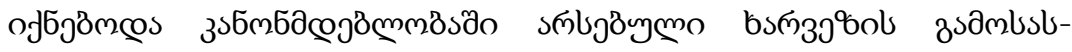




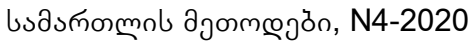

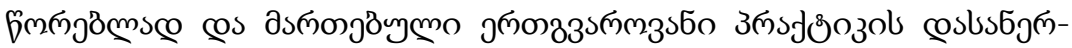
вsc. 


\title{
LEGAL QUALIFICATION OF AMMUNITION INTENDED FOR HUNTING SMOOTH-BORE FIREARMS ACCORDING TO THE CASE LAW
}

\section{Giorgi Dzindzibadze*}

\begin{abstract}
Georgia is one of the countries where firearms are removed from free civilian circulation, and the purchase of certain categories of firearms, with the right of storage or carrying, is possible only on the basis of a special permit issued by the Service Agency of the Ministry of Internal Affairs. After registering the weapon, it is possible to purchase ammunition for this weapon. According to the current version of the Criminal Code, the title of Article 236 reads as follows: Illegal purchase, storage, carrying, manufacturing, transportation, forwarding or sale of firearms (other than hunting smooth-bore firearms (shotguns)), ammunition, explosives or explosive devices, But, along with hunting smooth-bore firearms, the title of the article does not mention the ammunition intended for it, which poses some problems in terms of the legal qualification of the action.

With regard to Article 236 of the Criminal Code of Georgia, the Supreme Court of Georgia has established a uniform practice in some matters, which is provides by the city and appellate courts. The Cassation Chamber of the Criminal Court of the Supreme Court of Georgia clarifies that firearms and ammunition must be suitable for their intended use. as well as what is unlawful storage, carrying, transportation, shipment, key, manufacture. Despite numerous explanations from the Supreme Court regarding Article 236 of the Criminal Code, it appears that ammunition for smooth-bore firearms
\end{abstract}

* Ph.D. Candidate at Grigol Robakidze University. orcid.org/0000-00033167-6436. 


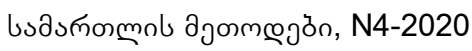

remained without explanation, which led to the courts accusing convicts of illegal purchase, storage and carrying of this category of ammunition.

Key words: Ammunition, Hunting, Smooth-bore, Firearms, Legal Qualification. 